\title{
Behavior of Certain Sugars and Sugar Alcohols in the Presence of Tetraborates-Correlation of Optical Rotation and Compound Formation
}

\author{
By Horace S. Isbell, Joseph F. Brewster, Nancy B. Holt, and Harriet L. Frush
}

\begin{abstract}
In the present investigation, the changes in the equilibrium specific rotation caused by the addition of either sodium or potassium tetraborate to solutions of D-glucose, D-fructose, L-sorbose, sucrose, mannitol, and sorbitol have been observed and the results interpreted. Measurements have been made for various concentrations of carbohydrates with fixed concentrations of borate, and for various concentrations of borate with fixed concentrations of carbohydrate. It was thus possible to observe independently the effect of variation in the concentration of either carbohydrate or borate. The results indicate that glucose, fructose, sorbose, and sorbitol form three borate compounds, that mannitol forms two, and sucrose one. The optical rotations of the compounds have been estimated, and the composition of the solutions discussed. Extensive tables have been included, giving the optical rotations of the above-mentioned carbohydrates in the presence of sodium and potassium tetraborate.
\end{abstract}

\section{Introduction}

In recent years large quantities of the polyhydric alcohols, sorbitol and mannitol, have been produced and have found use in many industries. The commercial applications make important the development of simple methods of analysis. The sugar alcohols, like nearly all sugar derivatives that do not contain an oxygen ring, have low optical rotatory power, but the addition of borates, molybdates, tungstates or certain other inorganic substances considerably increases the rotation and makes polarimetric methods of measurement possible. Although it has been more or less customary, since 1874 , to characterize the sugar alcohols by their optical rotations in aqueous solutions containing borax $[1],{ }^{1}$ there has been no uniform procedure and little emphasis on the effect of concentration. The purpose of this investigation was to obtain more comprehensive data concerning the effect of borates on the optical rotations of mannitol and sorbitol at various concentrations. As borates affect the optical rotations of the sugars as well as the sugar

1 Figures in brackets indicate the literature references at the end.of this paper. alcohols, similar studies appeared to be desirable on those sugars (glucose, fructose, sorbose, and sucrose) that are commonly associated with sorbitol and mannitol.

Another object of the investigation was to extend knowledge of the character of the boratecarbohydrate compounds, a subject of particular importance in relation to various polysaccharides. Thus, it is well known that the viscosity and physical properties of algins, plant gums, and mucilages are altered in striking manner by the addition of borates. It is believed that the information presented in this paper will be useful in interpreting the action of borates on these more complex substances. ${ }^{2}$

\section{Reactions of Borates and Carbohydrates}

\section{Prior Work}

It has been known for many years that polyhydroxy substances combine with boric acid any borates in solution with great ease and rapidity. The reactions are accompanied by extraordinarily

2 The methods described in this paper are being applied to the study of other carbohydrates, including the uronic acids. 
large changes in physical and chemical properties. Thus, the addition of mannitol to aqueous solutions of borax changes the reaction of the borax from strongly alkaline to strongly acid [2]. Information as to the character of the compounds formed has been derived from measurement of the changes in optical rotation, electrical conductivity, acidity, freezing point, solubility, and volume. Lambert first observed the effect of structure on compound formation [3], a subject that Magnanini studied extensively by conductivity measurements [4]. In a series of brilliant investigations extending over many years, Böeseken and coworkers developed Magnanini's method and ascertained the structural and configurational conditions necessary for the formation of borate compounds. $^{3}$ Originally Böeseken assumed that 1 molecule of a dihydroxy compound combines with 1 of boric acid with loss of water to form a cyclic compound (type A) having strong acid properties. The preparation by Hermans [6] of several crystalline compounds of this structure, but having only weak acid properties, led to a revision of the original concept and the conclusion that there are several classes of boric acid compounds differing widely in acid strength. The formulas that have been suggested are tabulated below

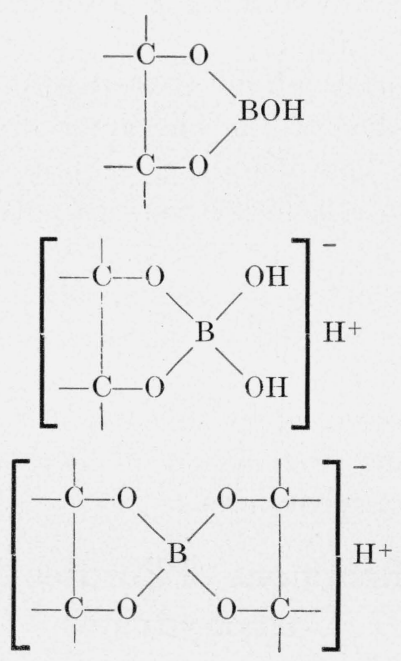

For convenience they will be designated hereafter as types $\mathrm{A}, \mathrm{BD}$ and $\mathrm{BD}_{2}$, respectively. Hermans considered structure $\mathrm{BD}_{2}$ as most probable for the strongly acid compounds, but recognized that compounds of the BD type may also be strongly

\footnotetext{
${ }^{3}$ A comprehensive list of Böeseken's early publications on this subject is found in footnote 3 on page 338 of [5].
}

acidic. Böeseken [7] justified the existence of compounds of pentavalent boron having four tetrahedrally arranged covalent bonds on the basis of the Lewis-Langmuir theory and pointed out the possibility of optical isomers for certain compounds of the $\mathrm{BD}_{2}$ type. The resolution of the strychnine salt of borodisalicylic acid into two optically active isomers confirmed the idea of the tetrahedral arrangement of the boron valences, and established the structure of the $\mathrm{BD}_{2}$ type conclusively [8].

The first compounds known to be of type A were prepared by Hermans [6], who found that a weakly acid volatile substance,

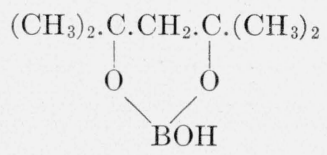

crystallizes readily from aqueous solutions con-taining equivalent quantities of boric acid and 2,4-dimethylpentane 2,4-diol. Several other representatives of this class were prepared. Ordinarily, compounds of type $\mathrm{A}$ are formed by dehydration of solutions containing the diol and boric acid or borate in proper proportion. Thus, by dehydration of mixtures of mannitol and boric acid,

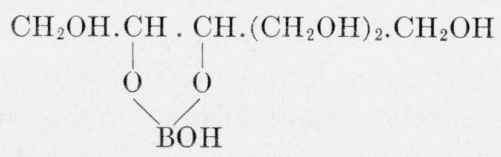

and

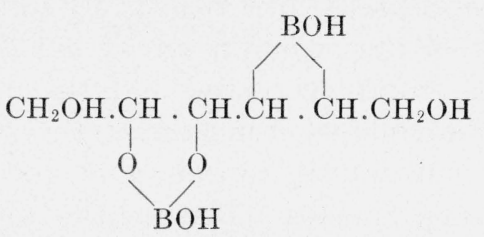

are obtained [9]. Partial hydrolysis of these compounds yields a crystalline acyclic mannitol borate considered to be 2-mannitol monoborate. Dehydration of boric acid mixtures containing ethylene glycol or 1,3-butylene glycol gives compounds of type A that are volatile [10]. Under like conditions glycerol gives a nonvolatile viscous mass, the nonvolatility of which is attributed to the formation of a third ester linkage between two diesterified molecules.

The evidence for compounds of the $\mathrm{BD}$ type is not so convincing as that for compounds of type $A$. 
Possibly the mannitol-boric acid compound of Fox and Gauge [11] having the empirical formula $\mathrm{C}_{6} \mathrm{H}_{15} \mathrm{O}_{8} \mathrm{~B}$ belongs to this class, and also the ciscycloheptane diol boric acid of Derx [12].

Numerous representatives of the $\mathrm{BD}_{2}$ type in the form of crystalline salts have been prepared, $[6,8]$. It was shown by Hermans that several compounds prepared by other workers (e. g., the salts of dipyrocatechol boric acid [13], potassium diborocitric acid [14], and possibly certain compounds prepared by Wohl and Neuberg [15] are of the $\mathrm{BD}_{2}$ type. A few of the crystalline acids have been obtained by heating the aniline or pyridine salts in a vacuum $[6,8]$, and it is possible that certain crystalline compounds of fructose, mannitol, and xylose are also of the $\mathrm{BD}_{2}$ type [16]. Vermaas [17] suggested that all 1,2, and 1,3 diols with hydroxyl groups in suitable positions are able to form compounds of type $\mathrm{A}$, in which the valence angle of the trivalent boron is $120^{\circ}$. Compounds of types $\mathrm{BD}$ and $\mathrm{BD}_{2}$, however, can be formed only when the hydroxyl oxygens are sufficiently close to allow the 4 covalencies of boron to assume a smaller angle, namely, $109^{\circ}$. This concept has been confirmed by X-ray diffraction measurements [18]. The cis diols ${ }^{4}$ that Böeseken classified as "favorable" meet this requirement and give rise to borate compounds of types $\mathrm{BD}$ and $\mathrm{BD}_{2}$ as well as to those of type $\mathrm{A}$. But for any single diol, it has not been possible to separate all three borate compounds in crystalline form.

For determining the configurations of the reducing sugars, advantage has been taken of the fact that the only cyclic diols that form compounds that increase the acidity of boric acid solutions are those with adjacent cis hydroxyl groups. This principle has been used by Böeseken and coworkers for establishing the configurations of many sugars [21]. For example, it was found that $a$-D-glucopyranose increases the acidity of boric acid, whereas $\beta$-D-glucopyranose does not. Hence the hydroxyls of carbons 1 and 2 of the alpha pyranose modification of glucose are in the cis position [22]. Moreover, the selective combination of certain modifications of the sugars with borates causes a shift in the equilibrium state.

${ }^{4}$ Certain disaccharides having adjacent cis hydroxyl groups do not appreciably increase the conductivity of boric acid and may even cause a decrease [19]. Böeseken [20] ascribed the anomalous behavior to the particular conformation of the strainless ring in these compounds.
The borate-sugar compound is decomposed by the addition of acid with regeneration of the sugar, and formation of a salt and boric acid. It was shown by Levy and Doisy [23] that this process is followed by a mutarotation caused by release of the sugar modification in the complex, and the subsequent establishment of the normal equilibrium state.

The prior work clearly shows the existence of borate-diol compounds of diverse types, but there is considerable uncertainty in regard to the character of the compounds present in aqueous solutions. Böeseken, Vermaas, and Küchlin [24] estimated the number of moles of polyol $(n)$ which form a strongly acid complex with 1 mole of boric acid, (1) from the change in $\mathrm{pH}$ upon the addition of the polyol to a fixed amount of boric acid, (2) from the change in $\mathrm{pH}$ during the neutralization of polyol-boric acid solutions, and (3) from freezing point measurements of borate-polyol solutions. By the three methods, $n$ was found to be 2 for fructose, mannitol, and a-mannitan. Tung and Chang, by potentiometric measurements of $\mathrm{pH}$ also found that $n$ equals 2 for several substances, notably fructose, mannitol, and xylose [16]. In contradiction to this evidence, Levy [25], using the freezing point data of Kahlenberg and Schreiner [26], calculated that 1 mole of sodium borate enters into combination with 1 mole of mannitol, and presented data to show that a 1:1 combination takes place with other carbohydrates. Other proportions were suggested by Darmois and Peyroux [27], but Bancroft and Davis [28] questioned the existence of any of the compounds in solution. Other contradictory literature was cited by Rippere and La Mer [10].

Although borate-polyol systems are extremely complex, and there is some conflicting evidence, it appears that an equilibrium involving compounds of types $\mathrm{A}, \mathrm{BD}$ and $\mathrm{BD}_{2}$ accounts most adequately for the experimental facts. Equilibrium systems of this character have been considered by Vermaas [17] and Böeseken [20]. Vermaas presented the following reaction scheme:

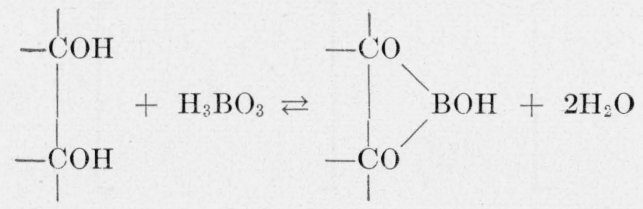




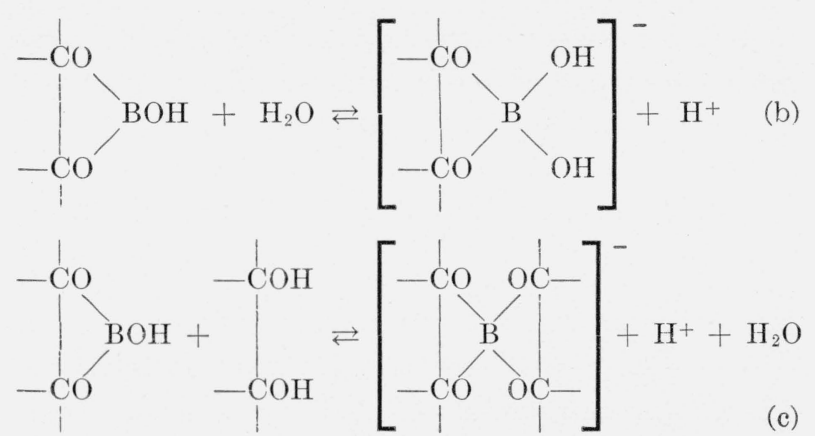

The primary reaction gives a compound of type A, which in turn is converted into substances of types $\mathrm{BD}$ and $\mathrm{BD}_{2}$ by reaction with either a molecule of water or a second molecule of diol. Under suitable conditions the process of reaction (a) undoubtedly takes place, but it may include the stepwise formation of an acyclic intermediate of the type

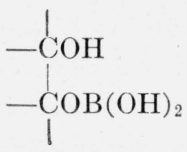

which Bremer [9] obtained by hydrolysis of a mannitol borate of type A. Reaction (c) seems questionable in light of the observation that the propylene glycol borate of type A does not combine with a second molecule of propylene glycol [10]. ${ }^{5}$ The inertness of the propylene glycol compound, however, may be due to an "unfavorable" structure rather than to the invalidity of the hypothetical reaction.

The following scheme was suggested by Böeseken $[20]$.

$$
\mathrm{H}_{3} \mathrm{BO}_{3}+\mathrm{H}_{2} \mathrm{O} \rightleftarrows\left[\begin{array}{lll}
\mathrm{HO} & \mathrm{OH} \\
& \mathrm{B} & \\
& & \mathrm{OHO}
\end{array}\right]^{-}+\mathrm{H}^{+}
$$
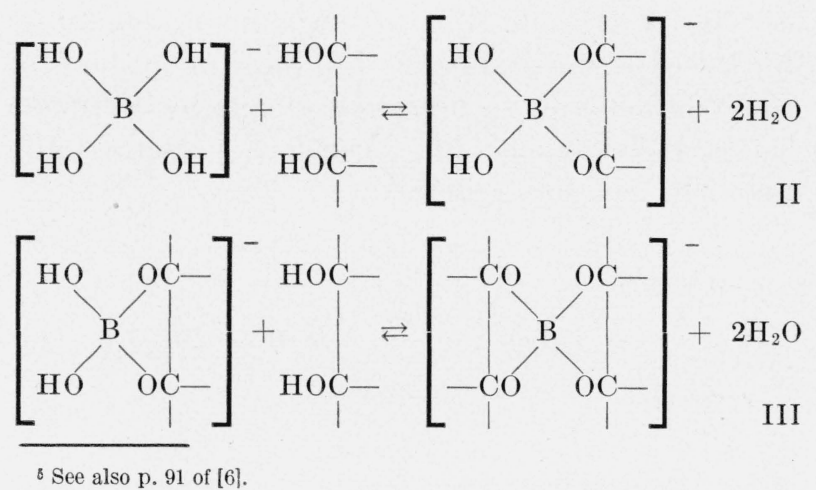

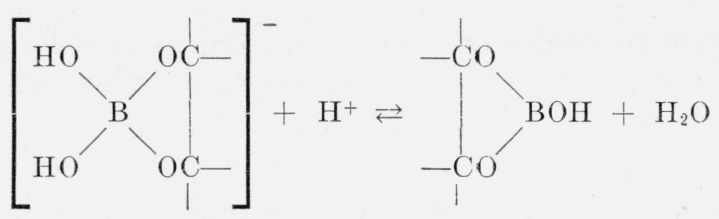

The first reaction gives an ion containing quadricovalent boron, which combines with the diol to yield a compound of type BD directly. Reaction $\mathrm{IV}$ is the same as reaction (b) of Vermaas' scheme, and appears to be relatively slow, at least with some diols.

In acid solutions the equilibrium for reaction I lies to the left. Consequently, only a small quantity of the quadricovalent borate ion is present and the tendency for the formation of ions $\mathrm{BD}^{-}$and $\mathrm{BD}_{2}^{-}$of reactions II and III is correspondingly small. The amounts of the complex acids formed from boric acid and a carbohydrate are sufficient to cause measurable changes in acidity but too small to detect by optical rotation measurements. In the presence of the alkali borates and tetraborates, however, the equilibrium for reaction I lies to the right, and the tendency for the formation of the ions $\mathrm{BD}^{-}$and $\mathrm{BD}_{2}^{-}$is high. Under these conditions large quantities of complex borates are formed, and it is possible to study compound formation of carbohydrates with borates or tetraborates by optical methods.

\section{General Discussion of the Results of the Present Investigation}

In this investigation, a study was made of the reactions of certain carbohydrates with sodium and potassium tetraborate. To obtain information concerning the compounds formed, solutions of D-glucose, D-fructose, L-sorbose, sucrose, mannitol, and sorbitol containing either sodium tetraborate or potassium tetraborate were studied polarimetrically. Measurements were made with solutions containing fixed amounts of the carbohydrate and various amounts of tetraborate, and with solutions containing fixed amounts of tetraborate and various amounts of carbohydrate.

As like molecular concentrations of sodium tetraborate and of potassium tetraborate were found to have like effects on the optical rotations of the substances investigated, the results obtained with the two salts are considered together. Sodium tetraborate is more readily obtained in pure condition and seems preferable for analytical pur- 
poses, but potassium tetraborate is more soluble and can be used over a wider range of concentration.

It was shown by Kahlenberg and Schreiner [26] that sodium tetraborate in solution is equivalent to equimolecular amounts of sodium borate and boric acid. As compound formation of carbohydrates with boric acid is too slight to be observed polarimetrically, the presence of boric acid can be neglected, and 1 mole of tetraborate can be considered to be equivalent to 2 moles of borate. If it be assumed that compounds of the $\mathrm{BD}$ and $\mathrm{BD}_{2}$ types are highly ionized and show little variation in ionization with concentration, and that a compound of type $\mathrm{A}$ is only slightly ionized, certain relationships can be drawn from Böeseken's equations, which appear to provide a reasonable interpretation of the complex changes observed in the optical rotations of carbohydrates in the presence of tetraborates.

The reactions may be expressed symbolically in the following manner: ${ }^{6}$

$$
\begin{aligned}
\mathrm{H}_{3} \mathrm{BO}_{3}+\mathrm{H}_{2} \mathrm{O} & \rightleftarrows \mathrm{B}^{-}+\mathrm{H}^{+} \\
\mathrm{B}^{-}+\mathrm{D} & \rightleftarrows \mathrm{BD}^{-}+2 \mathrm{H}_{2} \mathrm{O} \\
\mathrm{BD}^{-}+\mathrm{D} & \rightleftarrows \mathrm{BD}_{2}^{-}+2 \mathrm{H}_{2} \mathrm{O} \\
\mathrm{BD}^{-}+\mathrm{H}^{+} & \rightleftarrows \mathrm{A}+\mathrm{H}_{2} \mathrm{O}
\end{aligned}
$$

A system of this character would result in the equilibrium state represented somewhat arbitrarily in figure 1. This figure is similar to those used by Vermaas [17] and by Böeseken and Vermaas [29]. It includes, however, compounds of type $A$, and shows by the dotted lines, the direction of the changes that occur as the hydrogen ion concentration decreases. At a given tetraboratediol ratio, the heights of the curves would be expected to vary widely with concentration and to depend on the characteristics of the diol in question.

From mass law it follows that: ${ }^{7}$

$$
\begin{aligned}
& \frac{\left[\mathrm{BD}_{2}^{-}\right]}{\left[\mathrm{BD}^{-}\right]}=\frac{\mathrm{K}_{3}[\mathrm{D}]}{\left[\mathrm{H}_{2} \mathrm{O}\right]^{2}} \\
& {\left[\mathrm{BD}_{2}^{-}\right]=\frac{\mathrm{K}_{3}\left[\mathrm{BD}^{-}\right]^{2}}{\mathrm{~K}_{2}\left[\mathrm{~B}^{-}\right]}}
\end{aligned}
$$

\footnotetext{
${ }^{6} \mathrm{D}$ represents the carbohydrate (diol) and $\mathrm{B}^{-}$the ion $\left[\mathrm{BD}^{-}, \mathrm{BD}_{2}^{-}\right.$, and $\mathrm{A}$ represent the structures given on page ${ }_{130}$.

${ }^{7} \mathrm{~K}_{\mathrm{f}} \mathrm{K}_{2} \mathrm{~K}_{3}$ and $\mathrm{K}_{4}$ are the equilibrium constants of equations I, II, III' and IV.
} tion of $\mathrm{BD}^{-}$is favored by high concentrations of $\mathrm{D}$ and low concentrations of $\mathrm{H}_{2} \mathrm{O}$ and $\mathrm{B}^{-}$. Thus, compounds of the $\mathrm{BD}_{2}$ type should be formed preferentially in concentrated solutions of the carbohydrate containing small amounts of borate. Consequently, the change in optical rotation caused by the addition of small quantities of tetraborate to a carbohydrate solution can be ascribed principally to the formation of a compound of the $\mathrm{BD}_{2}$ type.

Compounds of types BD and A are favored by high borate concentrations according to eq 2 and 3. It follows from eq 1 and 4 that $\mathrm{BD}^{-}$is favored over $\mathrm{BD}_{2}^{-}$and $\mathrm{A}$ by dilution, and from eq 1 and 2 that $\mathrm{BD}^{-}$is favored over $\mathrm{BD}_{2}^{-}$by low concentrations of diol and high concentrations of borate. Hence, compounds of the BD type should predominate in dilute solutions containing large quantities of tetraborate and little carbohydrate.

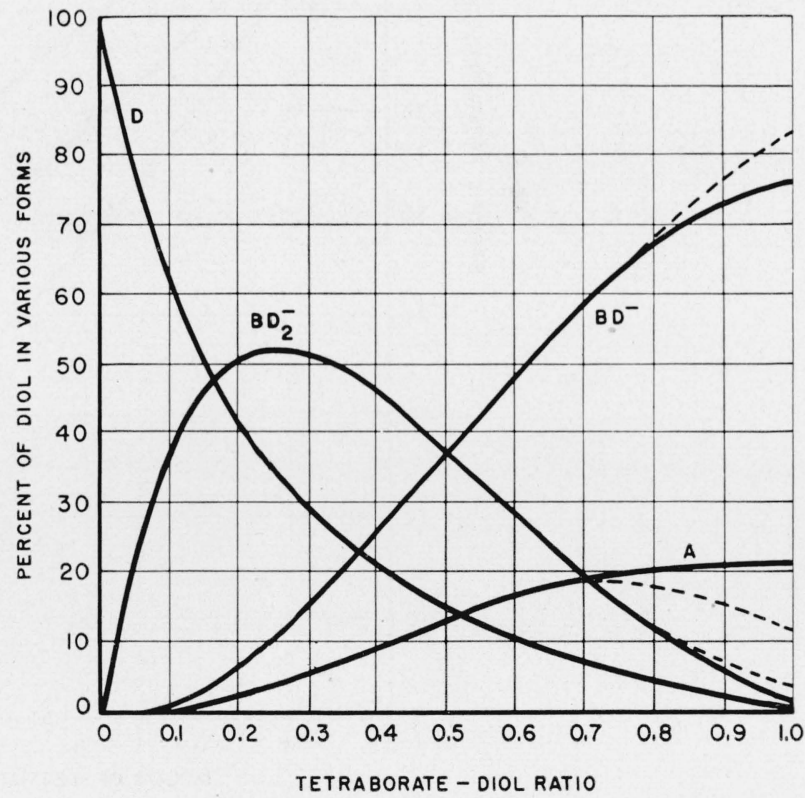

Figure 1. Hypothetical equilibrium diagram for the tetraborate-diol system.

$\mathrm{D}$, Percentage of uncombined diol; $\mathrm{BD}_{2}$, percentage of diol present as $\mathrm{BD}_{2}$ compound; $\mathrm{BD}$, percentage of diol present as $\mathrm{BD}$ compound; $\mathrm{A}$, percentage of diol present as typie A compound. . 
From eq 4 , it is seen that in a system containing $\mathrm{A}$ and $\mathrm{BD}^{-},[\mathrm{A}]$ varies inversely with $\left[\mathrm{H}_{2} \mathrm{O}\right]$, and $\left[\mathrm{BD}^{-}\right]$varies directly. Hence, the proportion of compounds of type $\mathbf{A}$ is higher in concentrated solutions than in dilute, and the change in optical rotation with change in concentration at a constant tetraborate-carbohydrate ratio provides a means of judging the direction and magnitude of the optical rotation of the compounds of type A.

The relative amounts of compounds of types A, $\mathrm{BD}$, and $\mathrm{BD}_{2}$ also vary with the hydrogen ion concentration. The work of Hermans, Böeseken, Vermaas, and others has shown that compounds of type A are only weakly acidic; whereas, the hydrogen compounds of the $\mathrm{BD}_{2}$ and $\mathrm{BD}$ types are strongly acidic. If, as we have assumed, com- pounds of type $\mathrm{A}$ are not ionized, and compounds of types $\mathrm{BD}_{2}$ and $\mathrm{BD}$ are completely ionized, the relation between concentrations of hydrogen ion and of $\mathrm{A}, \mathrm{BD}_{2}^{-}, \mathrm{BD}^{--}, \mathrm{D}$, and $\mathrm{B}^{-}$can be expressed by eq 3,4 , and 5 . From eq 4 and 5 , one would expect the ratios $\left[\mathrm{BD}^{-}\right]:[\mathrm{A}]$ and $\left[\mathrm{BD}_{2}^{-}\right]:[\mathrm{A}]$ to increase with decrease in hydrogen ion concentration. In general, as the tetraborate-carbohydrate ratio increases, the hydrogen ion concentration decreases, and $\left[\mathrm{BD}^{-}\right]$and $\left[\mathrm{BD}_{2}^{-}\right]$increase at the expense of $[\mathrm{A}]$. This effect is indicated by the dotted lines of figure 1 . In this study, consideration has not been given to the change in the degree of ionization of the borate with change in concentration or to differences between the optical rotations of the ionized and nonionized borate-diol

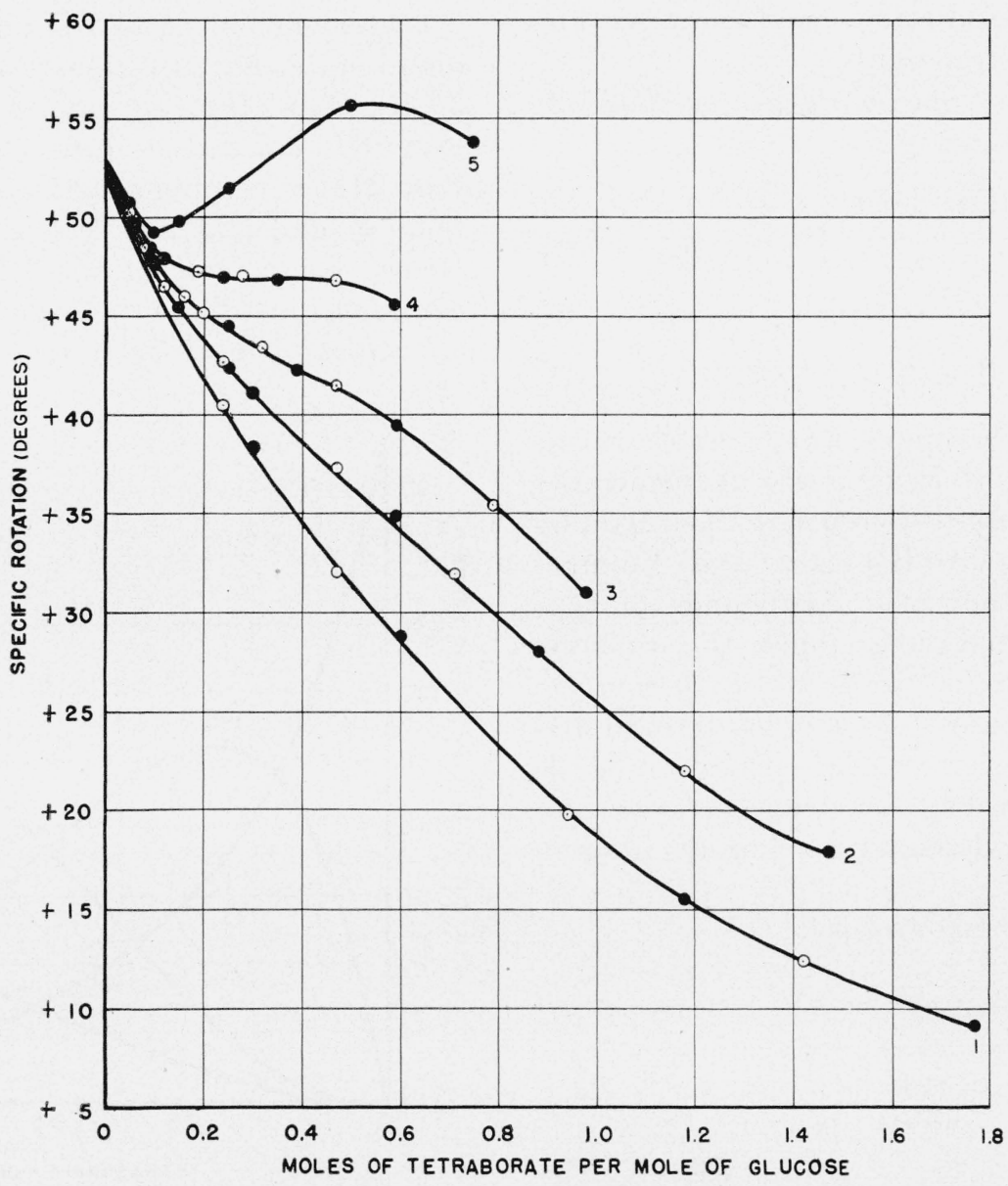

Figure 2. Specific rotation of glucose in the presence of alkali tetraborates.

, potassium tetraborate. 1,2 g of glucose per $100 \mathrm{ml} ; 2,4 \mathrm{~g}$ of glucose per $100 \mathrm{ml} ; 3,6 \mathrm{~g}$ of glucose per $100 \mathrm{ml} ; 4 ; 10 \mathrm{~g}$ of glucose per $100 \mathrm{ml} ; 5,25 \mathrm{~g}$ of glucose per $100 \mathrm{ml}$. 




FIGURE 3. Specific rotation of fructose in the presence of alkali tetraborates.

, potassium tetraborate. $1,2 \mathrm{~g}$ of fructose per $100 \mathrm{ml} ; 2,4 \mathrm{~g}$ of fructose per $100 \mathrm{ml} ; 3,6 \mathrm{~g}$ of fructose per $100 \mathrm{ml} ; 4,10 \mathrm{~g}$ of fructose per $100 \mathrm{ml}$.

compounds. Although these factors are of importance, they would not affect the qualitative conclusions that have been drawn.

It may be observed from the curvès of figures $2,3,4,5,6$, and 7 that in the presence of tetraborates, the optical rotations of certain carbohydrates vary in striking manner with the tetraborate-carbohydrate ratios and with the absolute concentrations. The presence of a maximum and minimum in the curves for glucose and fructose, and the inflection in the curves for sorbose are evidence for the formation of three compounds from each of these substances. The general contour of the curves for sorbitol likewise suggests the presence of three compounds, but the curves for mannitol give evidence for two compounds and those for sucrose for only one. The proportions of the borate-carbohydrate compounds responsible for the changes in optical rotation appear to vary with the tetraborate-carbohydrate ratio essentially as indicated in the curves of figure 1. The several carbohydrate-tetraborate systems are considered in detail in succeeding sections. 


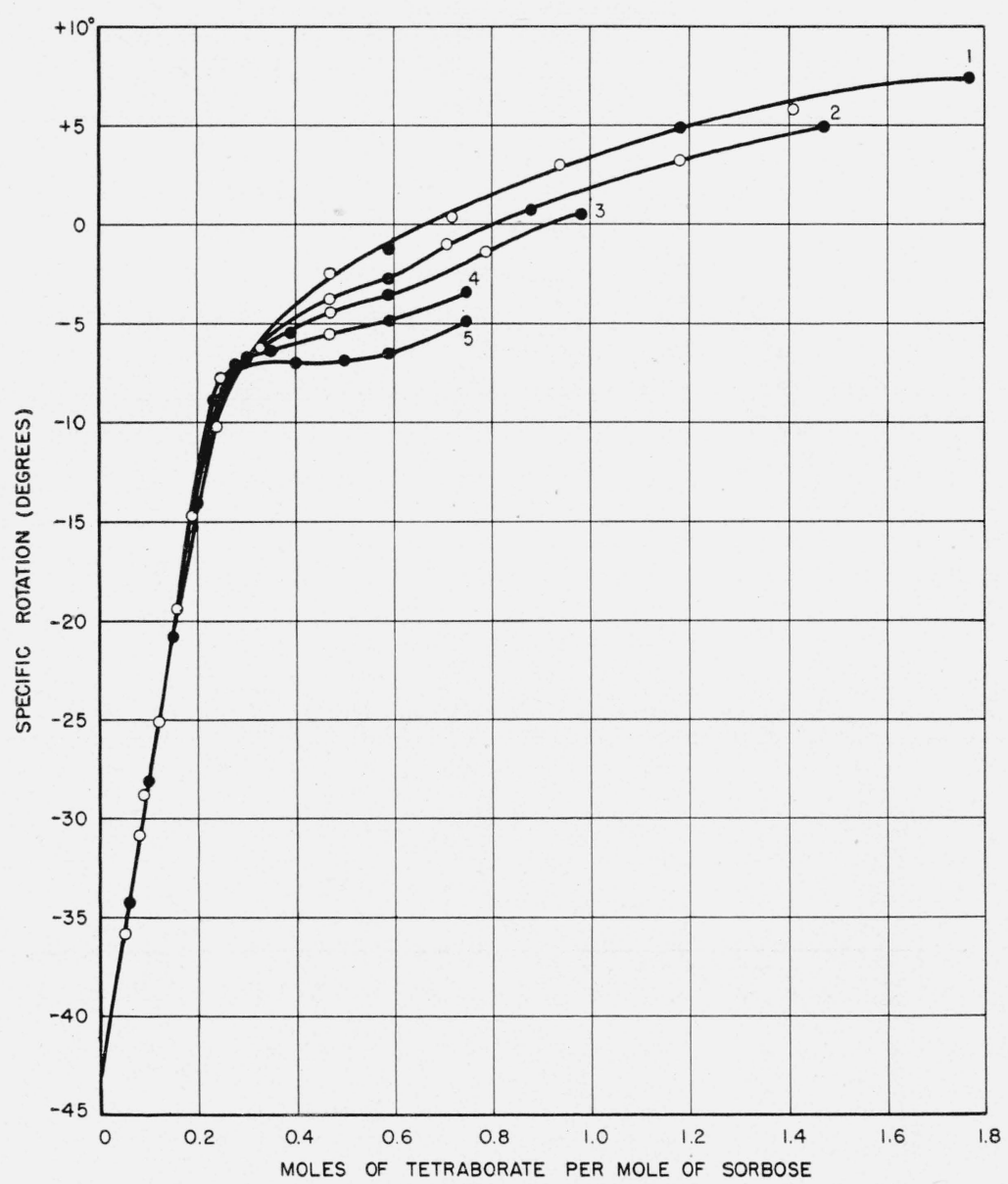

FIGURE 4. Specific rotation of sorbose in the presence of alkali tetraborates.

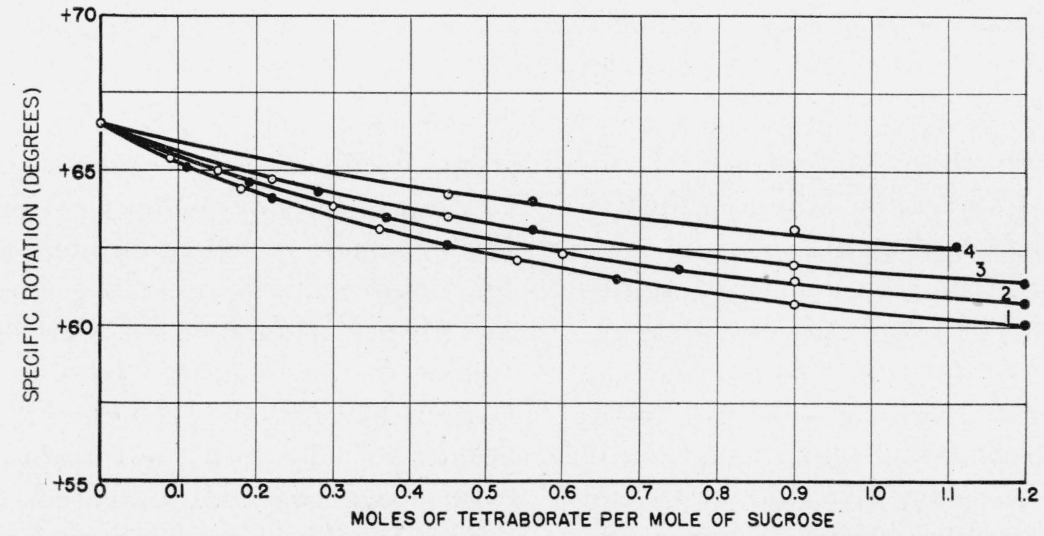

Figure 5. Specific rotation of sucrose in the presence of alkali tetraborates. 
ratio increases. ${ }^{8}$ As this value differs widely from the optical rotation of the free sugar $\left(+52^{\circ}\right)$ and does not vary appreciably with the concentration of the tetraborate, it may be assumed to correspond to the optical rotation of the BD compound. The existence of compounds having specific rotations of +40 and $-9^{\circ}$ will not account for the minimum and maximum observed in the rotations of concentrated solutions (figure 2, curve 5). Obviously, a compound at least as dextrorotatory as $+58^{\circ}$ (the maximum observed rotation) must be present. This compound is favored by high concentrations and a tetraborate-glucose ratio greater than 0.25. Hence, it is presumably of type A. The decrease in optical rotation with increasing tetraborate-glucose ratios above 0.5 can be ascribed to the formation of the $\mathrm{BD}$ compound by virtue of the decrease in hydrogen ion concentration (eq. 4, page 133).

TABLE 1. Specific rotation of D-glucose in aqueous solutions containing tetraborate

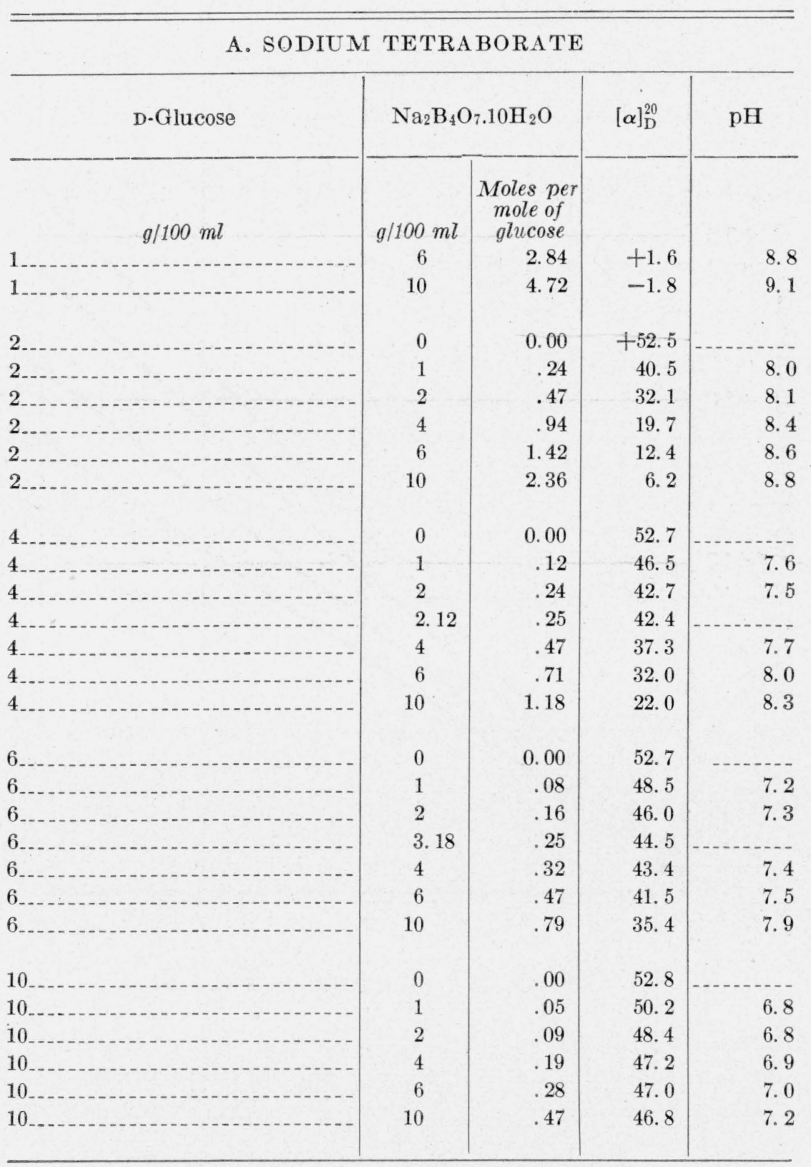

8 A levorotation, $\left(-8^{\circ}\right)$ for certain glucose-borate mixtures was reported by Coleman and Miller [34].
TABLE 1. Specific rotation of D-glucose in aqueous solutions containing tetraborate-Continued

B. POTASSIUM TETRA BORATE

\begin{tabular}{|c|c|c|c|c|}
\hline D-Glucose & \multicolumn{2}{|c|}{$\mathrm{K}_{2} \mathrm{~B}_{4} \mathrm{O}_{7} .4 \mathrm{H}_{2} \mathrm{O}$} & {$[\alpha]_{\mathrm{D}}^{20}$} & $\mathrm{pH}$ \\
\hline $0.5 \quad g / 100 \mathrm{ml}$ & $g / 100 m l$ & $\begin{array}{c}\text { Moles per } \\
\text { mole of } \\
\text { glucose } \\
7.08\end{array}$ & -4.3 & \\
\hline $2 \ldots$ & 0 & 0.00 & +52.5 & 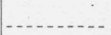 \\
\hline $2 \ldots \ldots \ldots$ & 1 & .30 & 38.3 & 7.8 \\
\hline $2 \ldots \ldots$ & 2 & .60 & 28.8 & 7. 9 \\
\hline $2 \ldots \ldots$ & 4 & 1.18 & 15.6 & 8.1 \\
\hline 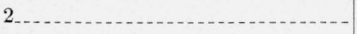 & 6 & 1. 77 & 9.2 & 8.7 \\
\hline $2 \ldots \ldots$ & 10 & 2.95 & 4.2 & 9.1 \\
\hline $4 \ldots \ldots$ & 0 & 0.00 & 52.7 & $-\cdots$ \\
\hline $4 \ldots$ & 1 & .15 & 45.4 & 7.3 \\
\hline $4 \ldots \ldots$ & 1. 70 & .25 & 42.4 & $\ldots$ \\
\hline $4 \ldots \ldots$ & 2 & .30 & 41.2 & 7.4 \\
\hline $4 \ldots$ & 4 & .59 & 34.9 & 7. 6 \\
\hline $4 \ldots \ldots$ & 6 & .88 & 28.0 & $\cdots$ \\
\hline $4 \ldots$ & 10 & 1. 47 & 17.9 & $\cdots$ \\
\hline $6 \ldots$ & 0 & 0.00 & 52.7 & - \\
\hline $6 \ldots$ & 1 & .10 & 47.7 & 7.1 \\
\hline $6 \ldots$ & 2 & .20 & 45.1 & 7.1 \\
\hline $6 \ldots$ & 2.54 & .25 & 44.6 &.- \\
\hline 6 & 4 & .39 & 42.3 & 7.2 \\
\hline $6 \ldots$ & 6 & .59 & 39.5 & 7.4 \\
\hline $6 \ldots$ & 10 & .98 & 31.0 & $\ldots$ \\
\hline $6 \ldots$ & 20 & 1. 96 & 17.3 & - n \\
\hline $10 \ldots$ & 0 & 0.00 & 52.8 & - - \\
\hline 10 & 1 & .06 & 49.6 & 6. 7 \\
\hline $10 \ldots$ & 2 & .12 & 47.9 & 6.7 \\
\hline $10 \ldots$ & 4 & .24 & 46.9 & 6.7 \\
\hline 10 & 6 & .35 & 46.8 & 6.8 \\
\hline $10 \ldots \ldots$ & 10 & .59 & 45.6 & 7.1 \\
\hline $15 \ldots$ & 12. 72 & .50 & 50.6 & $\cdots$ \\
\hline $20 \ldots \ldots$ & 8. 48 & .25 & 50.6 & - \\
\hline $20 \ldots \ldots$ & 10.0 & .30 & 51.3 & - \\
\hline $25 \ldots$ & 2.12 & .05 & 50.7 & \\
\hline $25 \ldots \ldots$ & 4. 24 & .10 & 49.1 & - \\
\hline $25 \ldots \ldots$ & 6. 36 & .15 & 49.9 & $\cdots$ \\
\hline $25 \ldots$ & 10.6 & .25 & 51.4 & (.... \\
\hline 25 & 21.2 & .50 & 55.7 & $\ldots$ \\
\hline $25 \ldots \ldots \ldots$ & 31.8 & .75 & 53.8 & (n) \\
\hline $30 \ldots$ & 25.44 & .50 & 57.0 & $-\infty$ \\
\hline 35 & 29.68 & .50 & 57.4 & (n) \\
\hline 40 s & 33.92 & .50 & 57.6 & - \\
\hline
\end{tabular}

a $\mathrm{Read}$ at $35^{\circ} \mathrm{C}$.

The complex relationships in the optical rotations shown in the curves of figure 2 arise from changes in the proportions of the free sugar and the three borate compounds, essentially as shown in figure 1 . At low tetraborate-glucose ratios, the concentration of the sugar is relatively high, and $\mathrm{BD}_{2}^{-}$is the principal product. As the tetraborate-glucose ratio increases, the concentration of the free sugar decreases, and hence, the ratios $\left[\mathrm{BD}_{2}^{-}\right]:\left[\mathrm{BD}^{-}\right]$and 
$\left[\mathrm{BD}_{2}^{-}\right]:[\mathrm{A}]$. The formation of the compound of type A shifts the optical rotation in the dextro direction, and accounts for the increase in optical rotation on the right-hand side of the minimum in curve 5 of figure 2 . As the tetraborate-glucose ratio increases further, the hydrogen ion concentration decreases. This factor leads to the formation of the BD compound, partially at the expense of $\mathrm{A}$, and accounts for the decrease in optical rotation following the maximum in curve 5 .

At a fixed tetraborate-glucose ratio, changes in concentration affect the relative amounts of the three compounds. In concentrated solutions compounds of type $\mathrm{A}$ and $\mathrm{BD}_{2}$ are present in larger amount, and account for the higher dextrorotations of these solutions; in dilute solutions at high tetraborate-glucose ratios the $\mathrm{BD}$ compound predominates to the exclusion of the others. The variation in the proportions of the several compounds with concentration accounts for the striking differences in the character of the curves obtained at different concentrations of glucose.

\section{D-Fructose}

The effect of boric acid and borates on the optical rotation of D-fructose has been studied by a number of workers $[27,31,35]$. It has been shown that fructose markedly increases the hydrogen ion concentration of aqueous boric acid, and that the effect is greatest at a concentration of 2 moles of fructose per mole of boric acid [36]. Other measurements have indicated that a difructose borate predominates under the conditions employed in the volumetric anaylsis of boric acid, and that a monofructose borate is present only when the concentration of fructose is less than 2 moles per mole of borate [37].

As fructose establishes an equilibrium containing both pyranose and furanose modifications [38], it might be expected to form derivatives of either modification. Levy and Doisy [23] observed that acidification of a solution containing fructose and borax results in a rapid mutarotation in the levo direction. The direction of the change is opposite to that of the mutarotation of crystalline $\beta$-Dfructopyranose. Hence, the predominating borate compound must contain an alpha fructopyranose, a fructofuranose, or an open-chain modification of the sugar. In light of the numerous possibilities, a definite structure cannot be assigned to the sugar component of any of the borate compounds at present.

The equilibrium specific rotations of fructose obtained in solutions at several concentrations in the presence of various amounts of sodium or potassium tetraborate are given in figure 3 and table 2. The specific rotations of solutions containing less than 0.25 mole of tetraborate per mole of fructose vary nearly linearly with the tetraborate-sugar ratio and show little change with change of concentration. These facts indicate that the product formed at low tetraboratefructose ratios is relatively stable, and that its amount is nearly proportional to the borate present. As the proportion of tetraborate is low, the compound is presumably of the $\mathrm{BD}_{2}$ type, and requires 0.25 mole of tetraborate per mole of fructose. The optical rotation can be estimated, as in the case of glucose, by extrapolation of the rotations observed at low tetraborate-fructose ratios to a ratio of 0.25 . The result so obtained indicates a specific rotation of approximately $-45^{\circ}$ based on the fructose content. The specific rotations in dilute solutions approach a limit at high tetraborate-fructose ratios of -22 to $-23^{\circ}$ expressed on the fructose content (fig. 9). This value corresponds to the optical rotation of a compound presumably of the $\mathrm{BD}$ type. At tetraborate-fructose ratios above 0.3 , the specific

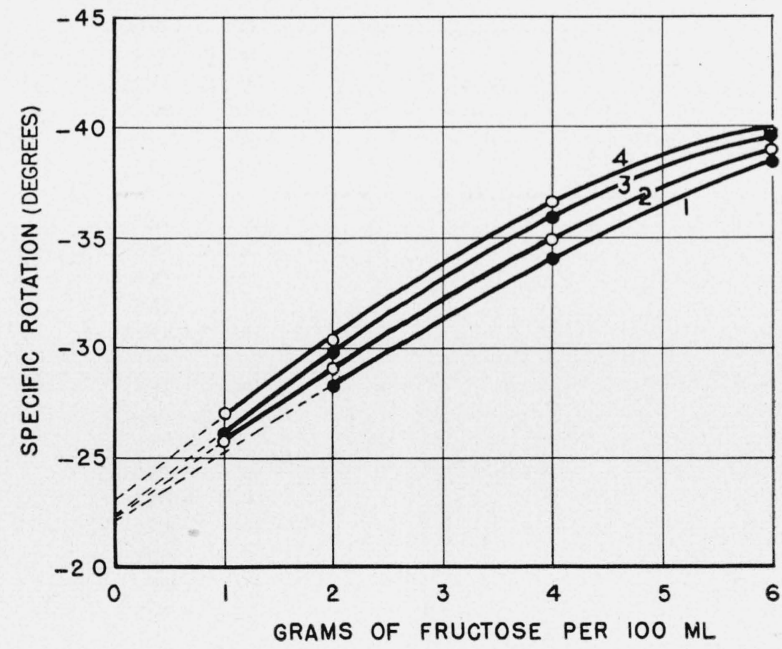

FIGURE 9. Limiting value for the specific rotation of fructose at low concentration in the presence of tetraborates, for estimation of the specific rotation of the $\mathrm{BD}$ compound.

0 , Sodium tetraborate; potassium tetraborate. $1,10 \mathrm{~g}$ of $\mathrm{K}_{2} \mathrm{~B}_{4} \mathrm{O}_{7} .4 \mathrm{H}_{2} \mathrm{O}$ per ml; 2, $10 \mathrm{~g}$ of $\mathrm{Na}_{2} \mathrm{~B}_{4} \mathrm{O}_{7} .10 \mathrm{H}_{2} \mathrm{O}$ per $100 \mathrm{ml} ; 3,6 \mathrm{~g}$ of $\mathrm{K}_{2} \mathrm{~B}_{4} \mathrm{O}_{7.4} \mathrm{H}_{2} \mathrm{O}$ per 100 $\mathrm{ml} ; 4,6 \mathrm{~g}$ of $\mathrm{Na}_{2} \mathrm{~B}_{4} \mathrm{O}_{7} .10 \mathrm{H}_{2} \mathrm{O}$ per $100 \mathrm{ml}$. 
rotations vary markedly with concentration (fig. $3)$. As in the case of glucose, the variation may be caused by the formation of a compound of type $A$ and by a shift in the relative proportion of $\mathrm{BD}_{2}^{-}$and $\mathrm{BD}^{-}$. It follows from eq 1 that at a given tetraborate-fructose ratio there must be relatively more $\mathrm{BD}_{2}^{-}$in concentrated solutions than in dilute. This accounts in part for the more levo rotations of concentrated solutions, but a system having only two compounds in addition to the free sugar will not account for both the maximum optical rotation found at a tetraboratefructose ratio of 0.3 to 0.5 , and the minimum, found at a ratio of 0.5 to 0.8 . The decrease following the maximum, shown in curve 4, shows the existence of a third compound, presumably of type $\mathrm{A}$, and having a levorotation of at least $-45^{\circ}$. The increase following the minimum may be attributed to changes in the proportion of $\mathrm{BD}^{-}$ and $\mathrm{A}$ with decrease in hydrogen ion concentration, as the tetraborate-fructose ratio is increased.

TABLE 2. Specific rotation of D-fructose in aqueous solutions containing tetraborate

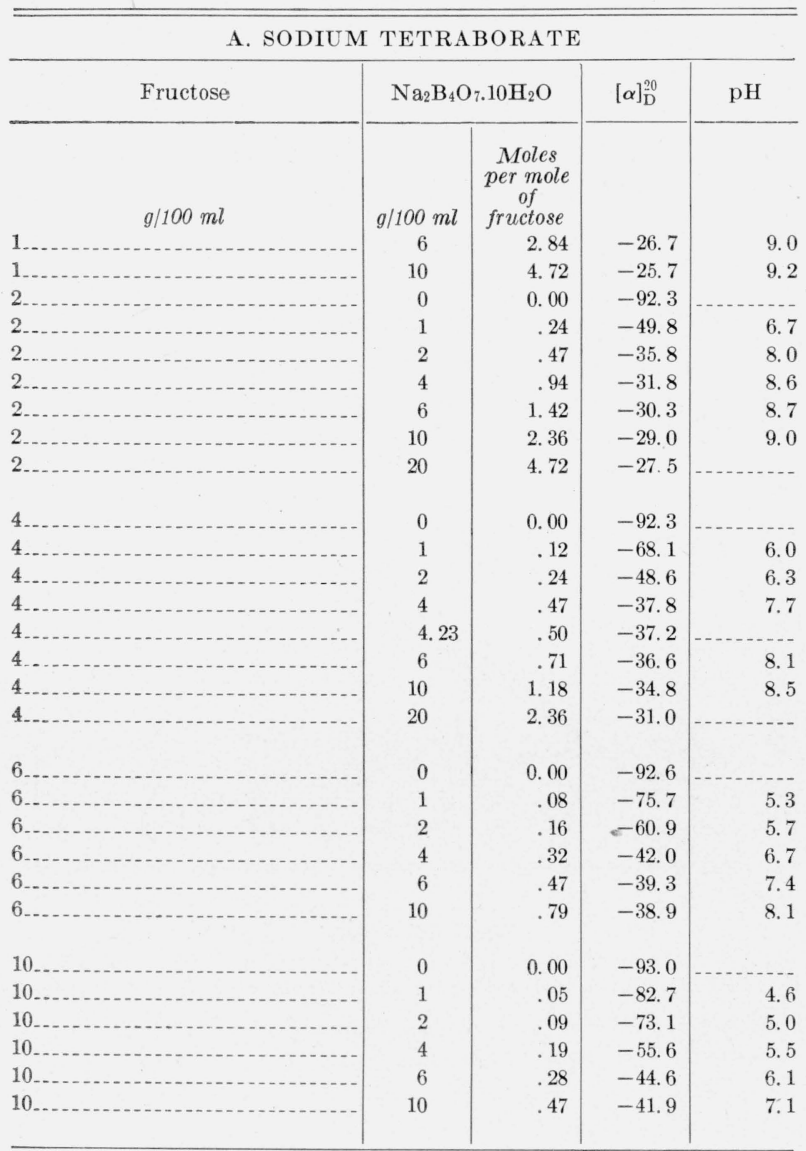

TABLE 2. Specific rotation of D-fructose in aqueous solutions containing tetraborate-Continued

B. POTASSIUM TETRABORATE

\begin{tabular}{|c|c|c|c|c|}
\hline Fructose & \multicolumn{2}{|c|}{$\mathrm{K}_{2} \mathrm{~B}_{4} \mathrm{O}_{7} .4 \mathrm{H}_{2} \mathrm{O}$} & {$[\alpha]_{\mathrm{D}}^{20}$} & $\mathrm{pH}$ \\
\hline $\begin{array}{r}g / 100 \mathrm{ml} \\
1\end{array}$ & $\begin{array}{c}g / 100 m l \\
6\end{array}$ & $\begin{array}{c}\text { Moles } \\
\text { per mole } \\
\text { of } \\
\text { fructose } \\
3.54\end{array}$ & -25.9 & 9.3 \\
\hline $1 \ldots$. & 20 & 11. 79 & -25.4 & $\ldots$ \\
\hline $2 \ldots \ldots$ & 0 & 0.00 & -92.3 & $\ldots$ \\
\hline $2 \ldots$ & 1 & .30 & -44.3 & 6.9 \\
\hline $2 \ldots \ldots$ & 2 & .59 & -33.8 & 7.8 \\
\hline $2 \ldots \ldots$ & 4 & 1.18 & -31.3 & 8.4 \\
\hline $2 \ldots$ & 6 & 1. 77 & -29.7 & 8.5 \\
\hline $2 \ldots$ & 10 & 2.95 & -28.2 & 8.8 \\
\hline $4 \ldots$ & 0 & 0.00 & -92.3 & $\ldots$ \\
\hline $4 \ldots$ & 1 & .15 & -62.5 & 5. 7 \\
\hline $4 \ldots \ldots$ & 2 & .30 & -42.7 & 6.3 \\
\hline $4 \ldots$ & 3.39 & .50 & -37.8 & $\ldots$ \\
\hline $4 \ldots \ldots$ & 4 & .59 & -36.9 & 7.3 \\
\hline $4 \ldots \ldots$ & 6 & .88 & -35.9 & 7.7 \\
\hline $4 \ldots$ & 10 & 1.47 & -34.0 & 8.5 \\
\hline $6 \ldots$ & 0 & 0.00 & -92.6 & .... \\
\hline $6 \ldots$ & 1 & .10 & -72.1 & 5.1 \\
\hline $6 \ldots$ & 2 & .20 & -54.0 & 5.5 \\
\hline $6 \ldots$ & 4 & .39 & -39.7 & 7.5 \\
\hline $6 \ldots$ & 5. 09 & .50 & -39.7 & $\ldots$ \\
\hline $6 \ldots$ & 6 & .59 & -39.4 & 7.1 \\
\hline $6 \ldots$ & 10 & .98 & -38.3 & 8.0 \\
\hline $6 \ldots \ldots$ & 20 & 1.96 & -35.2 & $\ldots$ \\
\hline 8 & 10 & .74 & -41.1 & -... \\
\hline $10 \ldots$ & 0 & 0.00 & -93.0 & $\cdots$ \\
\hline $10 \ldots \ldots$ & 1 & .06 & -80.6 & 4.5 \\
\hline 10 & 2 & .12 & -68.5 & 4.8 \\
\hline $10 \ldots$ & 4 & .24 & -48.6 & 5.3 \\
\hline $10 \ldots$ & 4. 24 & .25 & -47.0 & $\cdots$ \\
\hline $10 \ldots$ & 6 & .35 & -41.2 & 5.9 \\
\hline $10 \ldots \ldots$ & 6. 78 & .40 & -41.2 & 7.3 \\
\hline 10 & 7. 63 & .45 & -41.6 & $\ldots$ \\
\hline 10 & 8 & .47 & -41.6 & -..- \\
\hline $10 \ldots$ & 8.48 & .50 & -42.1 & .... \\
\hline $10 \ldots$ & 9.33 & .55 & -42.8 & $\ldots$ \\
\hline $10 \ldots \ldots$ & 10.18 & .60 & -42.7 & .... \\
\hline $10 \ldots \ldots$ & 11.87 & .70 & -42.8 & .... \\
\hline 10 & 15.26 & .90 & -42.8 & $\ldots$ \\
\hline 10 & 20 & 1.18 & -40.7 & - \\
\hline $12 \ldots$ & 10.17 & .50 & -42.8 & $\ldots$ \\
\hline $15 \ldots$ & 6.36 & .25 & -47.2 & $\ldots$ \\
\hline 20 & 8.48 & .25 & -47.2 & (-nons. \\
\hline
\end{tabular}

\section{L-Sorbose}

Insofar as known the effect of borates on the optical rotation of $\mathrm{L}$-sorbose has not been previously investigated, although it has beeñ shown [39] that L-sorbose greatly increases the conductivity of boric acid. The capacity of sorbose to combine with boric acid might arise from the favorable positions of the hydroxyls of carbons 1 and 2 in either the pyranose or the furanose modifications. In the alpha forms, the hydroxyl of carbon 
3 is also in a favorable position for the formation of a complex borate.

The results given in table 3 and figure 4 show that the optical rotations of sorbose solutions change from a levo to a dextro direction with the addition of increasing amounts of tetraborate. The curves are similar to those obtained for fructose and may be explained in like manner. As with fructose, the linear relationship, between the specific rotations and the tetraborate-sorbose ratios is evidence that the compound formed at ratios of less than 0.25 is relatively stable. The rotations at low tetraborate-sorbose ratios extrapolated to a ratio of 0.25 indicate that the specific rotation of the $\mathrm{BD}_{2}$ compound is approximately $-5^{\circ}$. The specific rotation of the compound favored by high tetraborate-sorbose ratios and presumably of the BD type, was found from the curves of figure 10 to be approximately $+16^{\circ}$ (expressed on the sorbose content). The inflec-

TABLE 3. Specific rotation of L-sorbose in aqueous solutions containing tetraborate

A. SODIUM TETRABORATE

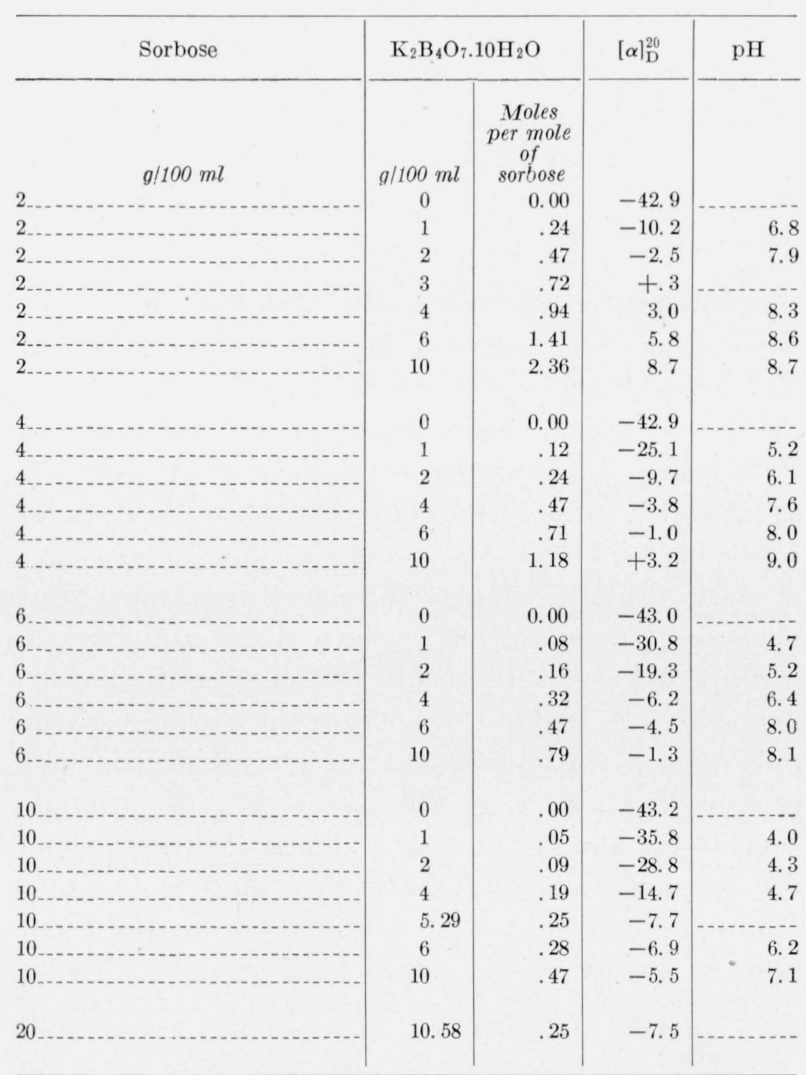

TABLE 3. Specific rotation of L-sorbose in aqueous solutions containing tetraborate-Continued

B. POTASSIUM TETRABORATE

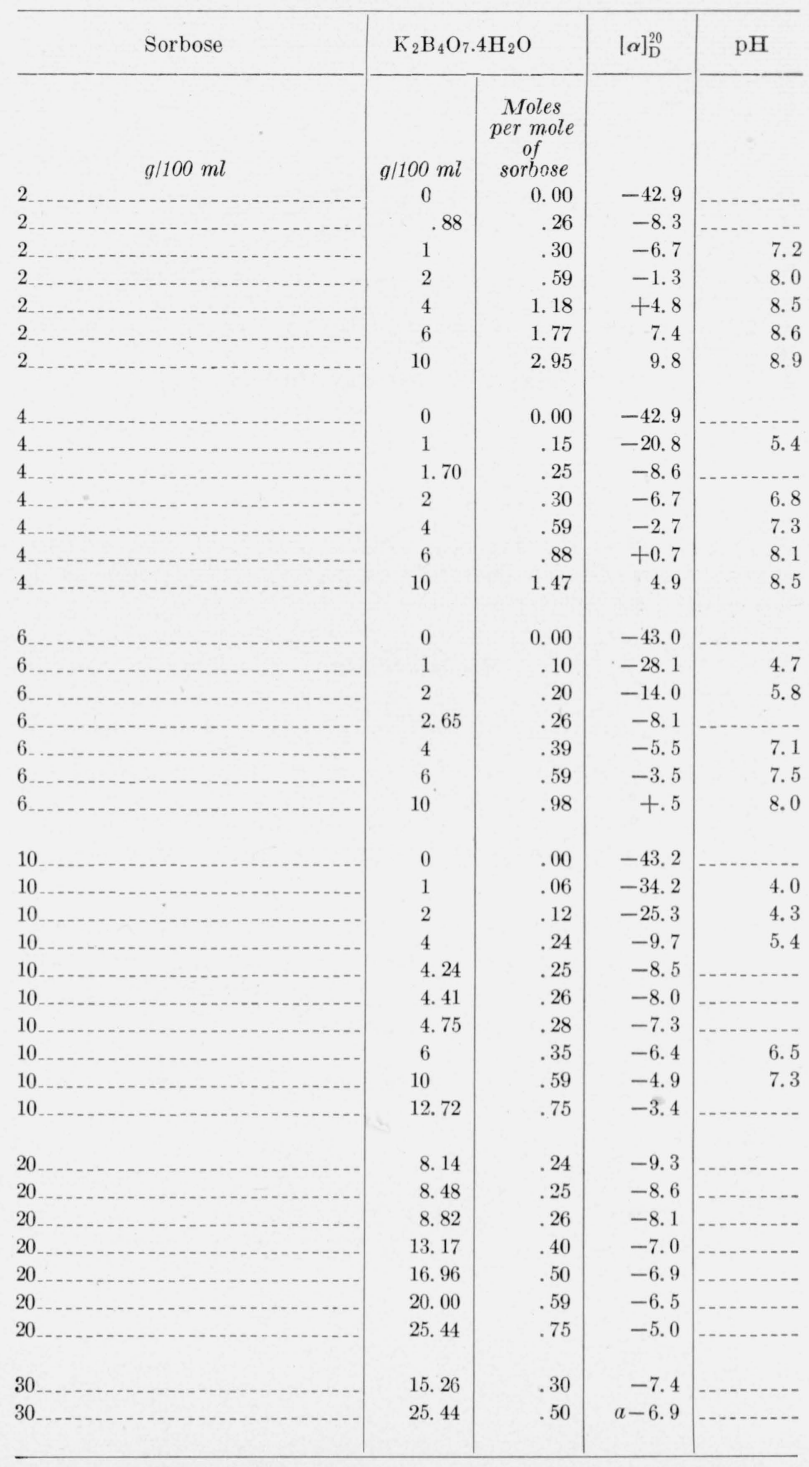

a Read at approximately $33^{\circ} \mathrm{C}$.

tions of the curves of figure 4 for high concentrations of sorbose indicate the presence of a third compound. As this compound is favored by high concentrations at tetraborate-sorbose ratios of more than 0.25 , it is presumably of type $\mathrm{A}$. To account for the alteration in optical rotations with concentration in the region of a tetraborate-sorbose ratio of 0.5 , the compound must be at least as levorotatory as $-7^{\circ}$. The increase in the slope of the curves as the tetraborate-sorbose 
ratio is increased above 0.5 can be attributed to a change in the ratio $[\mathrm{BD}]:[\mathrm{A}]$ caused by a decrease in the hydrogen ion concentration.

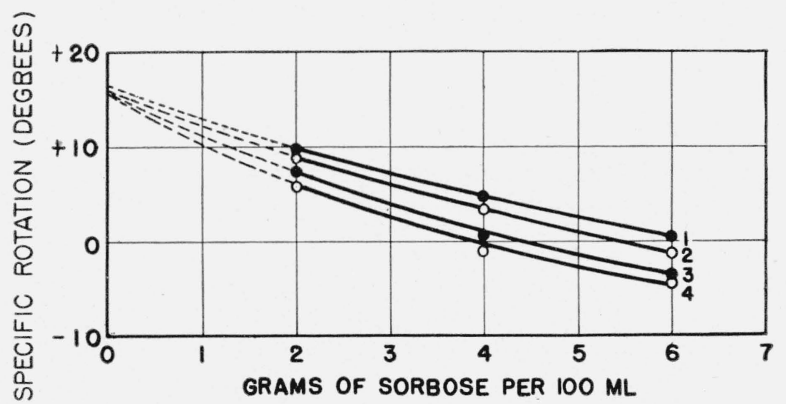

Frgure 10. Limiting value for the specific rotation of sorbose at low concentration in the presence of tetraborates, for estimation of the specific rotation of the $\mathrm{BD}$ compound.

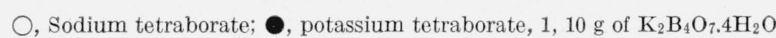
per $100 \mathrm{ml} ; 2,10 \mathrm{~g}$ of $\mathrm{Na}_{2} \mathrm{~B}_{4} \mathrm{O}_{7} .10 \mathrm{H}_{2} \mathrm{O}$ per $100 \mathrm{ml} ; 3,6 \mathrm{~g}$ of $\mathrm{K}_{2} \mathrm{~B}_{4} \mathrm{O}_{7} .4 \mathrm{H}_{2} \mathrm{O}$ per 100 $\mathrm{ml} ; 4,6 \mathrm{~g}$ of $\mathrm{Na}_{2} \mathrm{~B}_{4} \mathrm{O}_{7} .10 \mathrm{H}_{2} \mathrm{O}$ per $100 \mathrm{ml}$.

\section{Sucrose}

It was noted by Müntz in 1876 [40] that the addition of borax to solutions of sucrose causes a lowering of optical rotation. The change is not nearly so large as that found for most sugars, yet

TABLE 4. Specific rotation of sucrose in aqueous solutions containing tetraborate

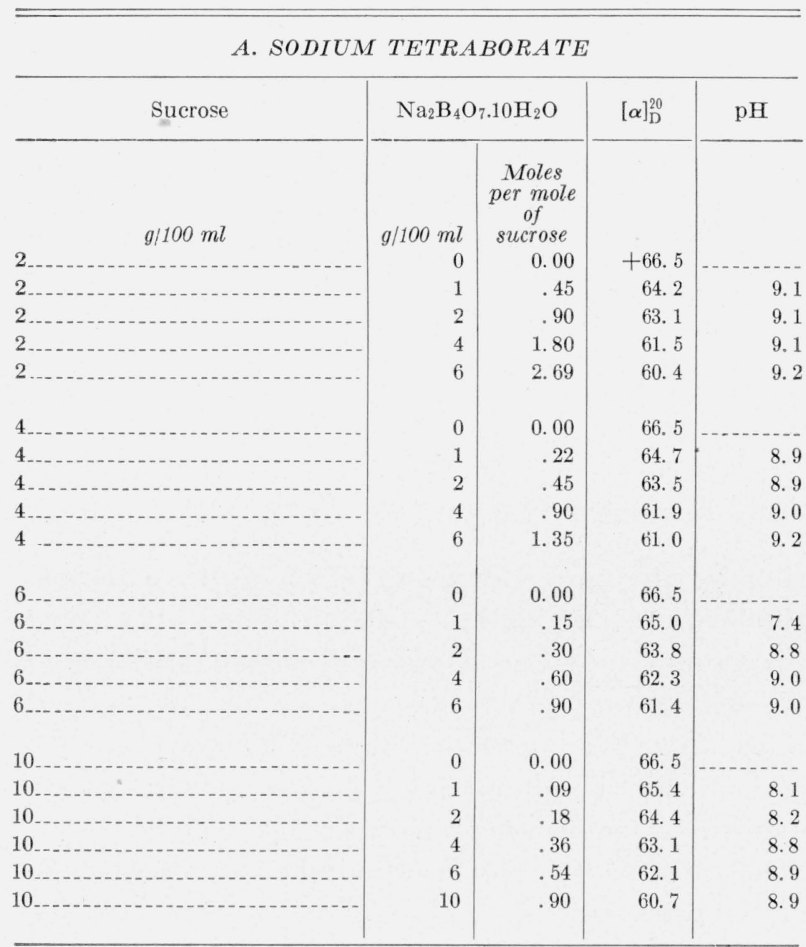

TABLE 4. Specific rotation of sucrose in aqueous solutions containing tetraborate-Continued

B. POTASSIUM TETRABORATE

\begin{tabular}{|c|c|c|c|c|}
\hline Sucrose & $\mathrm{K}_{2} \mathrm{~B}_{4} \mathrm{O}$ & $7.4 \mathrm{H}_{2} \mathrm{O}$ & {$[\alpha]_{\mathrm{D}}^{20}$} & $\mathrm{pH}$ \\
\hline $\quad$ / $100 \mathrm{ml}$ & $\begin{array}{r}g / 100 m l \\
0\end{array}$ & $\begin{array}{c}\text { Moles } \\
\text { per mole } \\
\text { of } \\
\text { sucrose } \\
0.00\end{array}$ & +66.5 & .... \\
\hline 2 & 1 & .56 & 64.0 & 9.0 \\
\hline $2 \ldots \ldots$ & 2 & 1.12 & 62.6 & 9.2 \\
\hline $2 \ldots+\ldots-1$ & 4 & 2. 24 & 60.9 & 9. 2 \\
\hline $2 \ldots \ldots \ldots$ & 6 & 3.36 & 60.0 & 9.3 \\
\hline $2 \ldots \ldots \ldots$ & 10 & 5.60 & 58.4 & 9.3 \\
\hline $4 \ldots \ldots$ & 0 & 0.00 & 66.5 & -- \\
\hline $4 \ldots \ldots$ & 1 & .28 & 64.4 & 9.0 \\
\hline $4 \ldots \ldots$ & 2 & .56 & 63.1 & 9.0 \\
\hline $4 \ldots$ & 4 & 1.12 & 61.4 & 9.1 \\
\hline $4 \ldots$ & 6 & 1. 68 & 60.3 & 9.1 \\
\hline $4 \ldots \ldots$ & 10 & 2. 80 & 58.8 & 9.3 \\
\hline $4 \ldots \ldots \ldots$ & 20 & 5.60 & 57.2 & $-\cdots$ \\
\hline $6 \ldots \ldots$ & 0 & 0.00 & 66.5 & -.. \\
\hline $6 \ldots \ldots$ & 1 & .19 & 64.6 & 8. 9 \\
\hline 6 & 2 & .37 & 63.4 & 8.9 \\
\hline 6 & 4 & .75 & 61.8 & 9.1 \\
\hline $6 \ldots$ & 6 & 1.12 & 60.7 & 9.1 \\
\hline 6 & 10 & 1. 90 & 59.3 & 9.3 \\
\hline 6 & 20 & 3.80 & 57.5 & $--\cdot$ \\
\hline $10 \ldots$ & 0 & 0.00 & 66.5 & -.. \\
\hline $10 \ldots$ & 1 & .11 & 65.1 & 8.6 \\
\hline 10 & 2 & .22 & 64.1 & 8.7 \\
\hline $10 \ldots$ & 4 & .45 & 62.6 & 8.8 \\
\hline $10 \ldots$ & 6 & .67 & 61.5 & 8.9 \\
\hline $10 \ldots$ & 10 & 1. 12 & 60.0 & 9.2 \\
\hline 10 & 20 & 2.24 & 57.8 & -- \\
\hline $20 \ldots$ & 20 & 1.12 & 59.0 & $\ldots$ \\
\hline
\end{tabular}

it is substantial and cannot be explained merely by the action of the alkali or by a salt effect. Sucrose has no adjacent cis hydroxyl groups, and consequently it cannot form compounds of the BD and $\mathrm{BD}_{2}$ types. Presumably for this reason, it does not appreciably affect the conductivity of boric acid solutions. ${ }^{9}$ The results, given in table 4 and figure 5 , show that the change in optical rotation varies with the concentration of both sugar and borate, but in contrast to the results obtained with glucose, fructose, and sorbose, the change is greatest in the most concentrated solutions. The optical rotations can be explained by the formation of a single sucrose-borate compound, which in dilute aqueous solutions dissociates in part. Presumably the compound is of type $A$ and is analogous to the compounds formed by 1,3-diols.

${ }^{9}$ See footnote 4 . 


\section{Mannitol}

In 1874 Vignon [1] observed that the optical rotation of mannitol is enhanced by the addition of borax and made extensive studies of the effect of the concentration of both mannitol and borax. Subsequently, Muller [30] made similar measurements and applied them to the quantitative estimation of mannitol. It was observed early that the addition of mannitol to solutions of boric acid causes a marked increase in acidity [2] and electrical conductivity. The effect has been studied extensively, and a method has been devised for the determination of boric acid by titration in the presence of mannitol [41].

Several mannitol-borates have been crystallized, but there is conflicting evidence in the literature as to the number and nature of the mannitol-borate compounds in solution. Fox and Gauge [11] reported a crystalline compound having acid properties, and the empirical formula $\mathrm{C}_{6} \mathrm{H}_{15} \mathrm{O}_{8} \mathrm{~B}$, but did not assign a structural formula. It has since been considered to be of the BD type [6]. A crystalline compound having 2 molecules of mannitol and one of borate was prepared by Tung and Chang [16], who suggested a formula of the $\mathrm{BD}_{2}$ type. Bremer [9] has disclosed the preparation of two amorphous mannitol-borate compounds of type $A$, in one of which two diol groups of the mannitol are combined with borate. As noted before, a crystalline acyclic mannitol borate considered to be 2-mannitol monoborate is formed by partial hydrolysis of the compounds of Bremer. ${ }^{10}$

From the optical rotations of a series of solutions containing increasing amounts of mannitol in the presence of decreasing amounts of borate, Böeseken and Vermaas [29] concluded that the solutions contained substances of the $\mathrm{BD}$ and $\mathrm{BD}_{2}$ types having molar rotations of +6.80 and $+3.26^{\circ}$, respectively. These values correspond to specific rotations of +37.4 and $+8.96^{\circ}$, based on the weight of mannitol.

The data given in table 5 and figure 6 show that mannitol has an exceptionally high capacity for

\footnotetext{
10 At the April 1939 meeting of the American Chemical Society in Baltimore, Md., W. H. Holst reported the preparation and identification of this 2-mannitol borate. He showed that the compound is different from the mannitol boric acid of Fox and Gauge, which has the same empirical formula. He considered the latter compound to be 1-mannitol monoborate. However, his evidence does not appear to preclude the cyclic 1,2 structure proposed by Hermans [6] for the Fox and Gauge compound. To date, Holst's work has not been published.
}

combination with borates. The mannitol-borate solutions are characterized first, in that the equilibrium specific rotation varies linearly with the tetraborate-mannitol ratio over a much wider range than that found for other carbohydrates, and second, in that the specific rotation is substantially independent of concentration at all tetraborate-mannitol ratios. The approximately linear relationship between the specific rotation and the tetraborate-mannitol ratio extends to a ratio of about 0.5. This is evidence for the formation of a relatively stable mannitol-borate compound having 1 molecule of mannitol for each borate group. The intercept of the linear curve with the ordinate corresponding to a tetraboratemannitol ratio of 0.5 indicates that the specific rotation of the compound is approximately $+22^{\circ}$.

TABLE 5. Specific rotation of mannitol in aqueous solutions containing tetraborate

A. SODIUM TETRABORATE

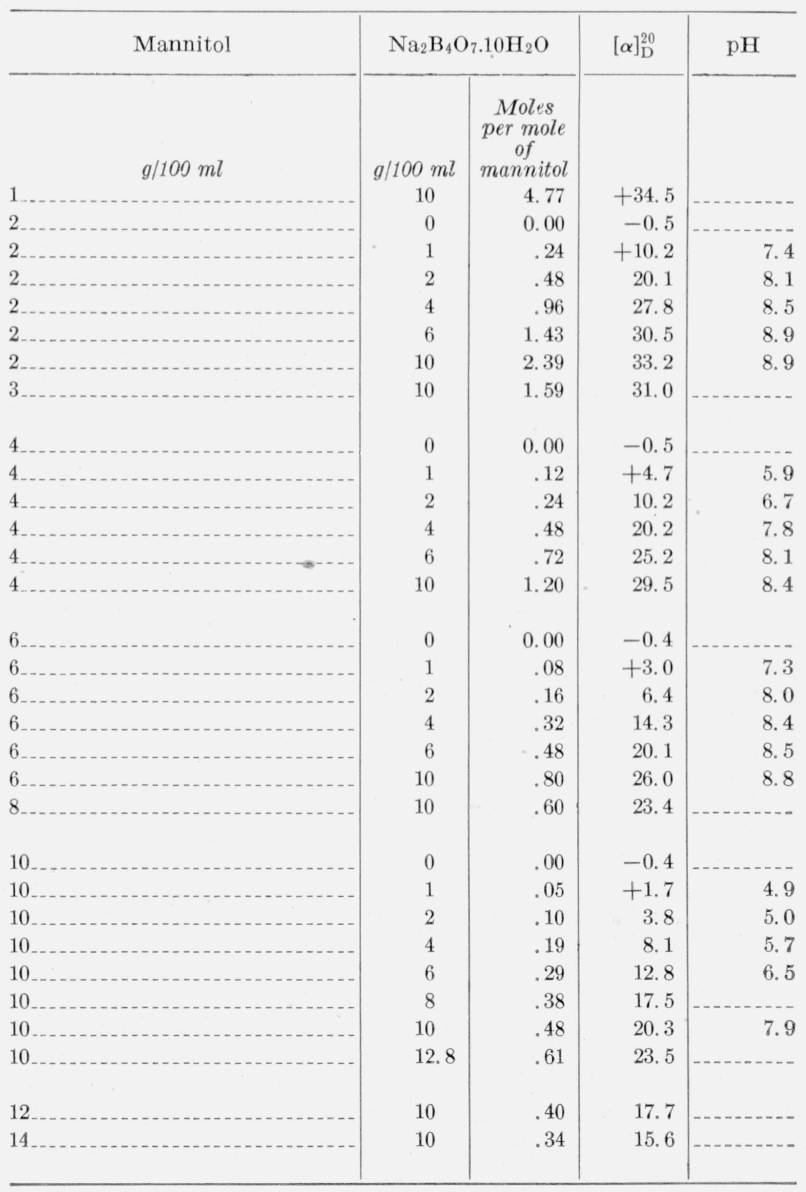


TABLE 5. Specific rotation of mannitol in aqueous solutions containing tetraborate-Continued

B. POTASSIUM TETRABORATE

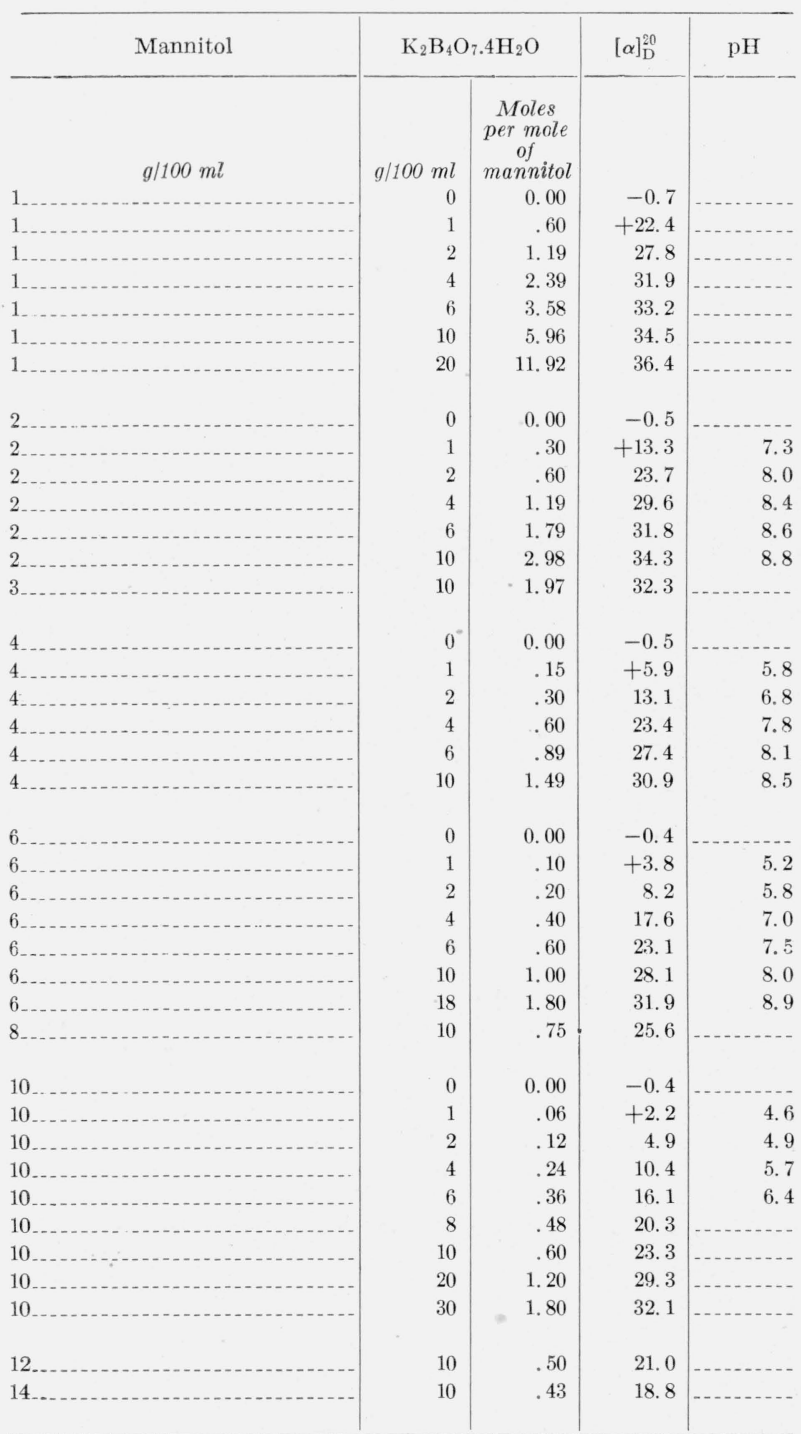

The compound might be of type $\mathrm{A}$, but this seems improbable because the proportion of the compound does not depend on concentration. It will be recalled that with glucose, fructose, and sorbose the amount of the type A compound varied widely with concentration. In view of the general character of the curve, it seems probable that the compound having a specific rotation of $+22^{\circ}$ is of the $\mathrm{BD}_{2}$ type in which $\mathrm{D}$ is only one-half of the mannitol molecule. That is, the mannitol molecule acts as a di-diol, and 4 hy- droxyls instead of 2 are combined with borate, as represented in formula $1 .^{11}$

Figure 11 shows that the optical rotation of mannitol in the presence of sodium tetraborate approaches a limiting value of approximately $+36^{\circ}$ with decreasing mannitol content. It is believed that this value approximates the optical rotation of a compound of the BD type (formula 2), again involving 4 hydroxyl groups of the mannitol molecule.

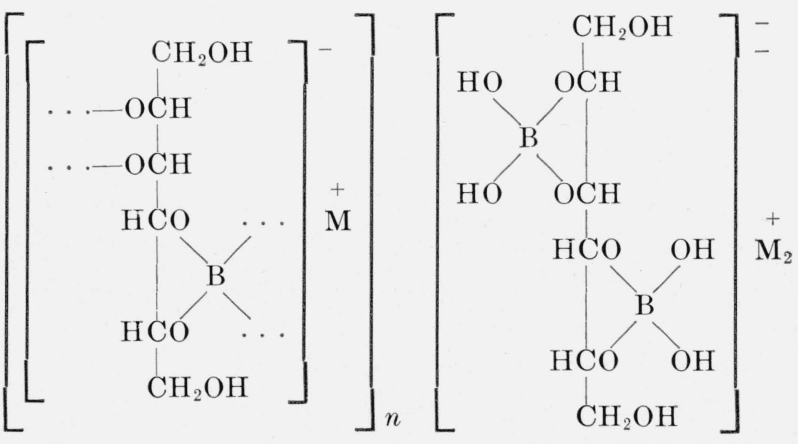

1.

2 .

The nearly complete absence of a concentration factor for the optical rotations at constant tetraborate-mannitol ratios is most surprising and has been found only for mannitol. The marked changes in the optical rotations of tetraborate-

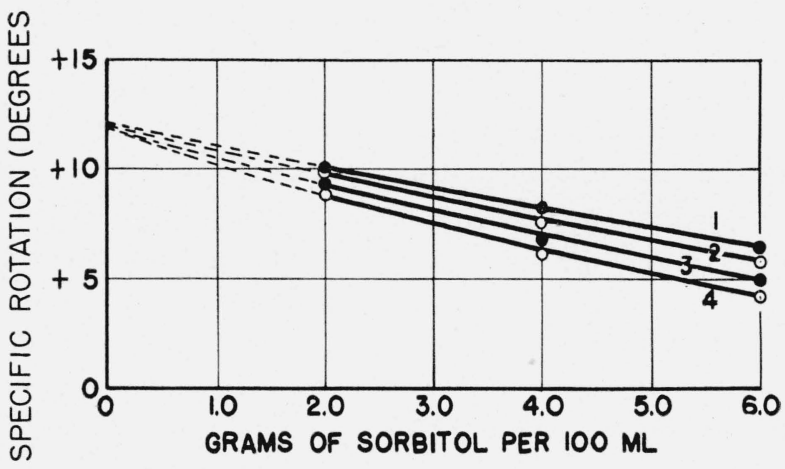

FIGURE 11. Limiting value for the specific rotation of mannitol at low concentration in the presence of tetraborates, for estimation of the specific rotation of the $\mathrm{BD}$ compound.

$\mathrm{O}$, Sodium tetraborate; $\boldsymbol{0}$, potassium tetraborate. $1,10 \mathrm{~g}$ of $\mathrm{K}_{2} \mathrm{~B}_{4} \mathrm{O}_{7} .4 \mathrm{H}_{2} \mathrm{O}$ per $100 \mathrm{ml} ; 2,10 \mathrm{~g}$ of $\mathrm{Na}_{2} \mathrm{~B}_{4} \mathrm{O}_{7} .10 \mathrm{H}_{2} \mathrm{O}$ per $100 \mathrm{ml} ; 3,6 \mathrm{~g}$ of $\mathrm{K}_{2} \mathrm{~B}_{4} \mathrm{O}_{7} .4 \mathrm{H}_{2} \mathrm{O}$ per $100 \mathrm{ml} ; 4,6 \mathrm{~g}$ of $\mathrm{Na}_{2} \mathrm{~B}_{4} \mathrm{O}_{7} .10 \mathrm{H}_{2} \mathrm{O}$ per $100 \mathrm{ml}$.

${ }^{11}$ As joining molecules by quadricovalent boron would increase the molecular weight, it may explain the striking effect of borates on the viscosity and other properties of polyuronides such as algin and certain gums, which contain a pair of cis hydroxyl groups in the repeating unit. The marked effect of boric acid on the physical properties of high molecular weight compounds not having neighboring cis hydroxyl groups may arise from polymerization by ester linkage through tribasic boric acid. 
glucose, tetraborate-fructose, and tetraboratesorbose solutions with change in concentration were attributed to changes in the proportions of compounds of the $\mathrm{BD}_{2}, \mathrm{BD}$, and $\mathrm{A}$ types. The lack of a marked change in the optical rotation of tetraborate-mannitol solutions with alteration in concentration may arise from a fortuitous compensation of optical rotations and from the lack of a substantial quantity of a compound of type A in the solutions investigated.

One of the objects of the present investigation was to obtain data for use in the quantitative analysis of polyhydric alcohols. In the pharmaceutical trade, it has been customary to ascertain the purity of mannitol by measuring the optical rotation of $10 \mathrm{~g}$ in a solution containing $12.8 \mathrm{~g}$ of borax, and sufficient water to make a volume of $100 \mathrm{ml}$. Under these conditions, $[\alpha]_{D}^{20}$ is reported to be +23 to $+24^{\circ}$ [42]; we have found that $[\alpha]_{D}^{20}=+23.5^{\circ} \pm 0.1$. Although $12.8 \mathrm{~g}$ of borax can be held in solution by $10 \mathrm{~g}$ of mannitol in a volume of $100 \mathrm{ml}$ at $20^{\circ} \mathrm{C}$, with smaller quantities of mannitol this quantity of borax will not dissolve. Less difficulty was experienced with solutions containing $10 \mathrm{~g}$ of borax per $100 \mathrm{ml}$, and this quantity was used with various quantities of mannitol to obtain the data reported in table 6 and figure 12. The optical rotations do not vary linearly with the concentration of the mannitol, but by extrapolation between values, the concentration of mannitol corresponding to any observed reading can be ascertained with an accuracy of about 1 part in 200 .

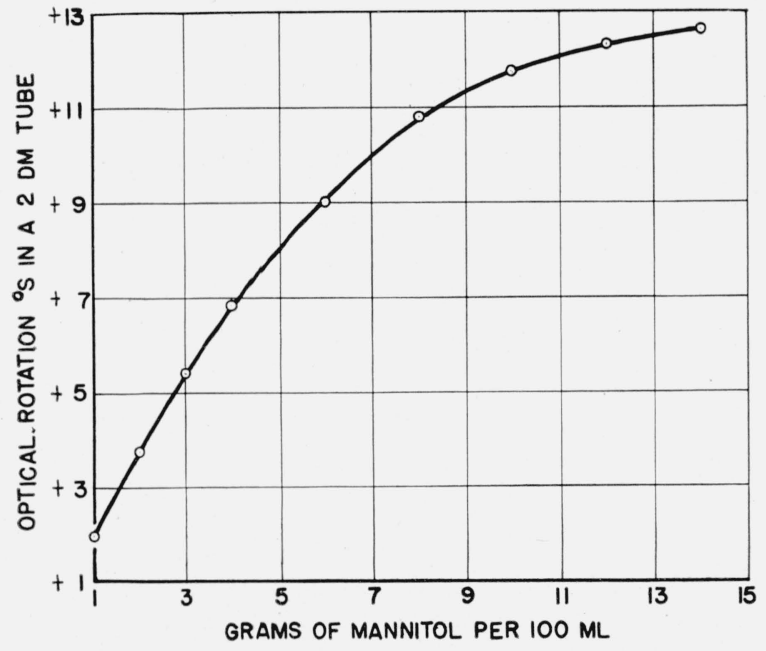

FIGURE 12. Optical rotation of mannitol in the presence of $10 \mathrm{~g}$ of $\mathrm{Na}_{2} \mathrm{~B}_{4} \mathrm{O}_{7} .10 \mathrm{H}_{2} \mathrm{O}$ per $100 \mathrm{ml}$ of solution.
TABLE 6. Optical rotation of mannitol in the presence of $10 \mathrm{~g}$ of $\mathrm{Na}_{2} \mathrm{~B}_{4} \mathrm{O}_{7} .10 \mathrm{H}_{2} \mathrm{O}$ per $100 \mathrm{ml}$ of solution

\begin{tabular}{|c|c|c|}
\hline Mannitol & $\begin{array}{l}\text { Observed } \\
\text { reading in } \\
\text { a } 2 \text {-dm } \\
\text { tube a }\end{array}$ & {$[\alpha]_{D}^{20}$} \\
\hline $\mathrm{g} / 100 \mathrm{ml}$ & ${ }^{\circ} \mathrm{S}$ & \\
\hline $1 \ldots \ldots$ & +1.99 & +34.5 \\
\hline $2+\ldots$ & 3.84 & 33.2 \\
\hline $3 \ldots \ldots$ & 5. 37 & 31.0 \\
\hline $4 \ldots \ldots$ & 6.82 & 29.5 \\
\hline $6 \ldots$ & 9.01 & 26.0 \\
\hline $8 \ldots$ & 10.81 & 23.4 \\
\hline $10 \ldots$ & 11. 73 & 20.3 \\
\hline 12 & 12. 27 & 17. 7 \\
\hline 14 & 12. 62 & 15.6 \\
\hline
\end{tabular}

a Angular degrees $=0.3462 \times{ }^{\circ} \mathrm{S}$.

\section{Sorbitol}

The effect of borax on the optical rotation of sorbitol was reported by Fischer and Stahel [43]. Böeseken and Vermaas [29] studied the optical rotations in a system in which both the sorbitol and borate were varied simultaneously. It has been found that the rotations of fixed quantities of sorbitol in the presence of increasing quantities of tetraborate are shifted in the same direction as those of mannitol, but the results differ in (1) the length and character of the linear portion of the curve, (2) the effect of concentration at fixed tetraborate-polyol ratios; and (3) the magnitude of the effect of tetraborate upon the rotation (fig. 7 and table 7). The curves for sorbitol are linear to a tetraborate-sorbitol ratio of only 0.16 , whereas the mannitol curves are linear to a tetraborate-mannitol ratio of approximately 0.5. Hence, there is no reason to assume that sorbitol acts as a di-diol, as does mannitol. Extrapolation of the optical rotations obtained at low tetraboratesorbitol ratios to a ratio of 0.25 gives a value of $+3^{\circ}$, which presumably corresponds to the specific rotation of a compound of the $\mathrm{BD}_{2}$ type. At high tetraborate-sorbitol ratios, the rotations approach a limit of +11 to $+12^{\circ}$ (fig. 13). Presumably, this value corresponds to the specific rotation of a compound of the BD type. The specific rotation at fixed tetraborate-sorbitol ratios above 0.2 decreases with increasing concentration. This indicates the formation of a compound of type A which is less dextrorotatory than the compound of either the $\mathrm{BD}_{2}$ or the $\mathrm{BD}$ type. 


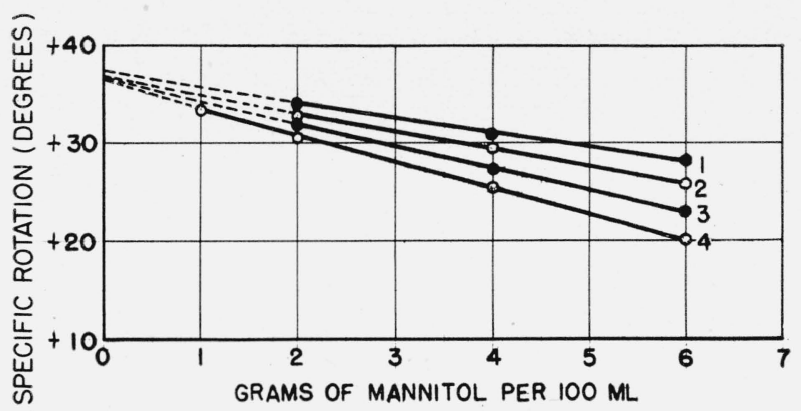

FIGURE 13. Limiting value for the specific rotation of sorbitol at low concentration in the presence of tetraborates, for estimation of the specific rotation of the $\mathrm{BD}$ compound.

. Sodium tetraborate; potassium, tetraborate. $1,10 \mathrm{~g}$ of $\mathrm{K}_{2} \mathrm{~B}_{4} \mathrm{O}_{7} .4 \mathrm{H}_{2} \mathrm{O}$ per $100 \mathrm{ml} ; 2,10 \mathrm{~g}$ of $\mathrm{Na}_{2} \mathrm{~B}_{4} \mathrm{O}_{7} .10 \mathrm{H}_{2} \mathrm{O}$ per $100 \mathrm{ml} ; 3,6 \mathrm{~g}$ of $\mathrm{K}_{2} \mathrm{~B}_{4} \mathrm{O}_{7} .4 \mathrm{H}_{2} \mathrm{O}$ per $100 \mathrm{ml} ; 4,6 \mathrm{~g}$ of $\mathrm{Na}_{2} \mathrm{~B}_{4} \mathrm{O}_{7} .10 \mathrm{H}_{2} \mathrm{O}$ per $100 \mathrm{ml}$.

TABLE 7. Specific rotation of sorbitol in aqueous solutions containing tetraborate

A. SODIUM TETRABORATE

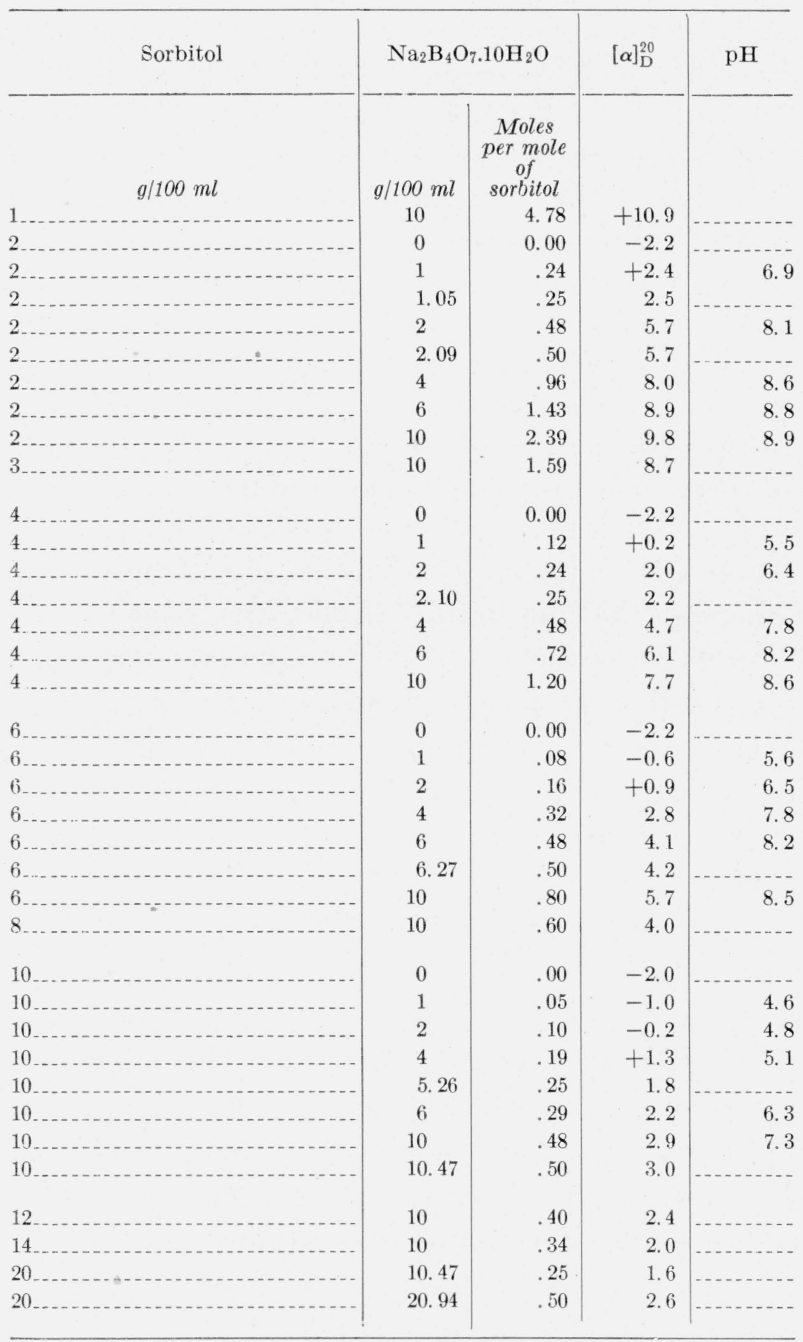

TABLE 7. Specific rotation of sorbitol in aqueous solutions containing tetraborate-Continued

B. POTASSIUM TETRABORATE

\begin{tabular}{|c|c|c|c|c|}
\hline Sorbitol & \multicolumn{2}{|c|}{$\mathrm{K}_{2} \mathrm{~B}_{4} \mathrm{O}_{7} .4 \mathrm{H}_{2} \mathrm{O}$} & {$[\alpha]_{\mathrm{D}}^{20}$} & $\mathrm{pH}$ \\
\hline$g / 100 \mathrm{ml}$ & $\begin{array}{r}\mathrm{g} / 100 \mathrm{ml} \\
10\end{array}$ & $\begin{array}{c}\text { Moles } \\
\text { per mole } \\
\text { of } \\
\text { sorbitol } \\
5.96\end{array}$ & +10.5 & \\
\hline $2 \ldots \ldots \ldots$ & 0 & 0.00 & -2.2 & -... \\
\hline $2 \ldots$ & 1 & .30 & +3.5 & 7.0 \\
\hline $2 \ldots \ldots$ & 2 & .60 & 6.5 & 8.0 \\
\hline $2 \ldots \ldots \ldots$ & 4 & 1. 19 & 8.8 & 8. 7 \\
\hline $2 \ldots \ldots$ & 6 & 1. 79 & 9.3 & 8.7 \\
\hline $2 \ldots$ & 10 & 2.98 & 10.0 & 8.8 \\
\hline 3 & 10 & 1.99 & 9.0 & $\ldots$ \\
\hline $4 \ldots$ & 0 & 0.00 & -2.2 & -... \\
\hline $4 \ldots \ldots$ & 1 & .15 & +0.4 & 5. 6 \\
\hline 4 & 2 & .30 & 2.6 & 6.7 \\
\hline $4 \ldots$ & 4 & .60 & 5.2 & 7. 7 \\
\hline $4 \ldots$ & 6 & .89 & 6.6 & 8.0 \\
\hline $4 \ldots$ & 10 & 1.49 & 8.2 & 8.4 \\
\hline $6 \ldots$ & 0 & 0.00 & -2.2 & .... \\
\hline (2)-1 & 1 & .10 & -0.2 & 5.6 \\
\hline $6 \ldots \ldots$ & 2 & .20 & +1.3 & 5. 7 \\
\hline 6 & 4 & .40 & 3.3 & 7.0 \\
\hline 6 & 6 & .60 & 4.6 & 7.6 \\
\hline $6 \ldots \ldots$ & 10 & 1.00 & 6.5 & 8.1 \\
\hline 8 & 10 & 0.75 & 5.0 & $\ldots$ \\
\hline $10 \ldots$ & 0 & .00 & -2.0 & $\ldots$ \\
\hline 10 & 1 & .06 & -0.8 & 4.5 \\
\hline 10 & 2 & .12 & +0.2 & 4.8 \\
\hline 10 & 4 & .24 & 1.7 & 5. 6 \\
\hline 10 & 6 & .36 & 2.4 & 6.4 \\
\hline 10 & 10 & .60 & 3.9 & 7. 3 \\
\hline 10 & 20 & 1. 19 & 5.9 &.- \\
\hline $12 \ldots \ldots$ & 10 & 0.50 & 2.9 & \\
\hline 14 & 10 & .43 & 2.4 & $\ldots$ \\
\hline
\end{tabular}

From a study of optical rotations and other data, Böeseken and Vermaas [29] concluded that the sorbitol-sodium borate system is not so simple as the mannitol-sodium borate system, and that at high borate-sorbitol ratios there is evidence for the existence of a bivalent ion, $\mathrm{B}_{2} \mathrm{D}^{=}$. Although this substance may be formed, the results of the present investigation do not provide clear evidence for its presence. If formed, it would be analogous to compound 2, page 142 , which is suggested for the mannitol system.

The quantitative determination of sorbitol at various concentrations by measurement of optical rotations in the presence of borax is not possible because the values are small, and the change in the observed optical rotation at constant tetraborate concentration shows a reversal with increasing amounts of sorbitol. This anomalous behavior is illustrated by the data of table 8 . 
TABLE 8. Optical rotation of sorbitol in the presence of $10 \mathrm{~g}$ of $\mathrm{Na}_{2} \mathrm{~B}_{4} \mathrm{O}_{7} \cdot 10 \mathrm{H}_{2} \mathrm{O}$ per $100 \mathrm{ml}$ of solution

\begin{tabular}{|c|c|c|}
\hline Sorbitol & $\begin{array}{l}\text { Observed } \\
\text { reading in } \\
\text { a 2-dm } \\
\text { tube a }\end{array}$ & {$[\alpha]_{\mathrm{D}}^{20}$} \\
\hline $\mathrm{g} / 100 \mathrm{ml}$ & ${ }^{\circ} \mathrm{S}$ & \\
\hline $2 \ldots$ & 1.13 & 9.8 \\
\hline $3 \ldots$ & 1.51 & 8.7 \\
\hline 4 & 1. 78 & 7. 7 \\
\hline $6 \ldots$ & 1. 98 & 5. 7 \\
\hline 8. & 1.85 & 4. 0 \\
\hline $10 \ldots$ & 1. 68 & 2. 9 \\
\hline $12 \ldots \ldots$ & 1. 66 & 2.4 \\
\hline $14 \ldots \ldots$ & 1.62 & 2,0 \\
\hline
\end{tabular}

a Angular degrees $=0.3462 \times^{\circ} \mathrm{S}$.

\section{Experimental Details}

\section{Purification of Tetraborates}

(a) Sodium tetraborate $\left(\mathrm{Na}_{2} \mathrm{~B}_{4} \mathrm{O}_{7} \cdot 10 \mathrm{H}_{2} \mathrm{O}\right)$

Borax, C. P. grade, was recrystallized from water by following the procedure recommended for standard borax for use in acidimetry [44].

\section{(b) Potassium tetraborate $\left(\mathrm{K}_{2} \mathrm{~B}_{4} \mathrm{O}_{7} \cdot 4 \mathrm{H}_{2} \mathrm{O}\right)$}

Potassium tetraborate hydrates having 4, 5, and 5.5 molecules of water of crystallization have been reported [45]. The commercial product, labeled a pentahydrate, ordinarily has an indefinite amount of water. The potassium tetraborate used in this investigation contained 4 molecules of water of crystallization and was prepared in the following manner: $500 \mathrm{~g}$ of boric acid was suspended in $750 \mathrm{ml}$ of water, and treated with $295 \mathrm{~g}$ of $\mathrm{C}$. P. potassium hydroxide dissolved in $600 \mathrm{ml}$ of water. The mixture was heated to dissolve the boric acid and was then filtered. The filtrate was evaporated to $750 \mathrm{ml}$, cooled to $30^{\circ} \mathrm{C}$, seeded with potassium tetraborate tetrahydrate, and allowed to crystallize under constant agitation. After 3 hours the crystals were separated and washed with ice water. The product was recrystallized by dissolving it in a minimum quantity of hot, 5-percent aqueous potassium hydroxide. The substance was allowed to crystallize as before, separated by filtration, washed thoroughly with cold water, and dried at room temperature in air. The product so obtained gave the following analysis [46]: Calculated for $\mathrm{K}_{2} \mathrm{~B}_{4} \mathrm{O}_{7} \cdot 4 \mathrm{H}_{2} \mathrm{O}: \mathrm{K}_{2} \mathrm{O}, 30.83 ; \mathrm{B}_{2} \mathrm{O}_{3}$, 45.59. Found: $\mathrm{K}_{2} \mathrm{O}, 31.0 ; \mathrm{B}_{2} \mathrm{O}_{3}, 45.7$.

\section{Purification of Sugars and Sugar Alcohols}

The glucose and sucrose used in the investigation were NBS Standard Samples, dried at $65^{\circ} \mathrm{C}$ in a vacuum oven. The levulose was purified by crystallization from a 90 -percent aqueous solution with the addition of ethyl alcohol, and the sorbose and mannitol were recrystallized from water. The sorbitol was purified in the following manner: 1 part by weight of commercial sorbitol was dissolved in 3 parts of pyridine by heating on the steam bath. The solution was filtered through a Büchner funnel coated with a decolorizing carbon. The filtrate was seeded with crystals of the sorbitol-pyridine complex, stirred for several hours at room temperature, and placed in a refrigerator overnight. The crystalline material that formed was collected on a Büchner funnel and washed with a mixture of 2 parts of ether and 1 part of pyridine. The pyridine complex was recrystallized twice from 3 parts of hot pyridine and then decomposed by heating for 18 hours at $65^{\circ} \mathrm{C}$ in a vacuum oven. The product thus obtained was recrystallized from 3 parts of hot 95-percent ethyl alcohol by allowing the solution after seeding to cool over a period of 24 hours without stirring. Under these conditions anhydrous sorbitol crystallizes in large rosettes of fragile needles that can be readily separated by filtration. ${ }^{12}$ The crystals were collected on a funnel and after a second crystallization, were air-dried, and finally dried to constant weight at $65^{\circ} \mathrm{C}$ in a vacuum oven.

\section{Measurement of Optical Rotation}

The solutions for the measurement of optical rotation were prepared by weighing the required amounts of carbohydrate and tetraborate into a volumetric flask. The mixture was dissolved in water, and the volume of the solution was adjusted at $20^{\circ} \mathrm{C}$. In a few cases it was necessary to warm the solution slightly to effect complete dissolution of the materials. In all cases, the solutions were allowed to stand at $20^{\circ} \mathrm{C}$ for at least 2 hours or until the optical rotation had become constant. Readings were made with a Bates saccharimeter, in a water-jacketed, $4-\mathrm{dm}$ tube at $20^{\circ} \mathrm{C}$ and were checked by a second observer. The values given in the tables were obtained from at least two separate determinations, in which the observed rotations

\footnotetext{
12 If crystallization occurs rapidly, bulky masses of microscopic needles form, which are difficult to separate from the mother liquor.
} 
agreed within $0.1^{\circ} \mathrm{S}$. The saccharimeter readings were converted to angular degrees by use of the conventional factor, 0.3462 . Some of the measurements reported in the tables were made on supersaturated solutions, but in these cases, care was taken to be certain that the solutions remained optically clear until the measurements were completed.

\section{Summary}

The present study indicates that the addition of either sodium or potassium tetraborate to a solution containing glucose gives rise to a diglucose borate having a specific rotation of about $+40^{\circ}$ (expressed on the glucose content). This substance exists in equilibrium with a monoglucose borate having a specific rotation of about $-9^{\circ}$ and a third compound whose rotation is at least $+58^{\circ}$. The proportion of the diglucose borate having a rotation of $+40^{\circ}$ is highest when the tetraborate-glucose ratio is about 0.25 . As the ratio is increased above 0.25 , the proportion of this compound decreases with the formation of the levorotatory monoglucose borate and the substance whose rotation is at least $+58^{\circ}$. The former compound is favored by dilute solutions and high tetraborateglucose ratios; the proportion of the latter compound is highest in concentrated solutions at a tetraborate-glucose ratio of about 0.5 , and decreases as the tetraborate-glucose ratio increases, presumably because of the accompanying decrease in the hydrogen ion concentration. According to the concentration, and the tetraborate-glucose ratio, the equilibrium specific rotation of D-glucose in the presence of tetraborate varies from +58 to $-9^{\circ}$.

Similar studies with D-fructose, L-sorbose, and sorbitol show that these substances react with tetraborates in essentially the same manner as D-glucose. In each case, evidence was obtained for the existence of three complex borates. The compounds favored by a tetraborate-carbohydrate ratio of 0.25 have specific rotations of approximately $-45^{\circ},-5^{\circ}$ and $+3^{\circ}$, based on the weights of fructose, sorbose, and sorbitol, respectively; the compounds of the same carbohydrates favored by dilution and high tetraborate-carbohydrate ratios have specific rotations of approximately $-22^{\circ},+16^{\circ}$, and $+12^{\circ}$. In each case, inflections in the curves and the effect of concentration indicate the presence of a third compound.

The mannitol-tetraborate system differs markedly from the other systems investigated in that the specific rotation depends almost completely on the tetraborate-mannitol ratio, and at a fixed ratio does not vary with concentration. The change in optical rotation with increasing tetraborate-mannitol ratio is linear to a ratio of 0.5 . This is evidence that a relatively stable compound having a mannitol-borate ratio of $1: 1$ and a specific rotation of $+22^{\circ}$ is formed. It is believed that four hydroxyl groups of mannitol are involved, and that mannitol acts as a di-diol. At high tetraborate-mannitol ratios. the optical rotation approaches a limit of $+36^{\circ}$. Presumably this rotation corresponds to that of a second mannitolborate compound. A table for the quantitative determination of mannitol from measurements of optical rotations in the presence of tetraborates is given.

The optical rotation of sucrose is somewhat decreased by the addition of either sodium or potassium tetraborate. The alteration is greatest in concentrated solutions, and is explained by compound formation. There is no evidence for more than one sucrose-borate compound.

\section{References}

[1] L. Vignon, Ann. Chim. Phys. [5] 2, 440 (1874).

[2] D. Klein, Bul. soc. chim. [3] 29, 357 (1878).

[3] A. Lambert, Compt. rend. 108, 1016 (1889).

[4] G. Magnanini, Z. physik. Chem. 6, 58 (1890).

[5] P. H. Hermans, Z. physik. Chem. 113, 338 (1924).

[6] P. H. Hermans, Z. anorg. Chem. 142, 83 (1925).

[7] J. Böeseken, Proc. Akad. Amsterdam 26, 97 (1923).

[8] J. Meulenhcff, Z. anorg. Chem. 142, 373 (1925).

[9] C. Bremer, U. S. Patent 2,223,948 (1940); U. S. Patent 2,224,011 (1940).

[10] R. E. Rippere and V. K. La Mer, J. Phys. Chem. 4;, 204 (1943).

[11] J. J. Fox and A. J. H. Gauge, J. Chem. Soc. 99, 1078 (1911).

[12] H. G. Derx, Rec. trav. chim. 41, 340 (1922).

[13] J. Böeseken, A. Obreen, and A. van Haeften, Rec. trav. chim. 37, 184 (1917).

[14] E. Scheibe, Pharm. Z. Russ. 18, 257, 289 (1879); 19, 513 (1880) ; Pharm. J. Trans. [3] 11, 389 (1880).

[15] A. Wohl and C. Neuberg, Ber. deut. chem. Ges. 32, 3488 (1899).

[16] J. Tung and H. Chang, J. Chinese Chem. Soc. 9, 125 (1942). 
[17] N. Vermaas, Rec. trav. chim. 51, 67 (1932).

[18] P. H. Hermans, Rec. trav. chim. 5\%, 333 (1938).

[19] I. R. Verschuur, Rec. trav. chim. 47, 123, 423 (1928).

[20] J. Böeseken, Rec. trav. chim. 61, 82 (1942).

[21] J. Böeseken, A. H. Kirstjens, and C. E. Klamer, Proc. Akad. Amsterdam 18, 1654 (1916); J. Böeseken, and H. Couvert, Rec. trav. chim. 40, 354 (1921); J. Böeseken, Rec. trav. chim. 61, 77 and 663 (1942).

[22」J. Böeseken, Ber. deut. chem. Ges. 46, 2622 (1913).

[23] M. Levy and E. A. Doisy, J. Biol. Chem. 84, 749 (1929).

[24] J. Böeseken, N. Vermaas, and A. T. Küchlin, Rec. trav. chim. 49, 711 (1930).

[25] M. Levy, J. Biul. Chem. 84, 763 (1929).

[26] L. Kahlenberg and O. Schreiner, Z. physik. Chem. 20, 547 (1896).

[27] E. Darmois and R. Peyroux, Compt. rend. 193, 1182 (1931).

[28] W. D. Bancroft and H. L. Davis, J. Phys. Chem. 34, 2479 (1930).

[29] J. Böeseken and N. Vermaas, Rec. trav. chim. 54, 853 (1935).

[30] J. A. Muller, Bul soc. chim. 11, 329 (1894).

[31] E. Rimbach and O. Weber, Z. physik. Chem. 51, 473 (1905).

[32] M. Murgier and E. Darmois, Atti $\mathrm{X}^{\circ}$ congr. int. chim. 2. 737 (1938).
[33] Y. Tuzuki, Bul. Chem. Soc. (Japan) 16, 23 (1941).

[34] G. H. Coleman and A. Miller, Proc. Iowa Acad. Sci. 49257 (1942).

[35] F. I. Berenshtein and A. U. Shpakovskii, Ukrain. Khem. Zhur. 11, 433 (1936).

[36] F. I. Berenshtein and L. N. Aisenberg, Ukrain. Khem. Zhur. 8, 307 (1933).

[37] H. Schäfer, Z. anorg. allgem. Chem. 247, 96 (1941).

[38] H. S. Isbell and W. W. Pigman, J. Research NBS 20, 773 (1938) RP1104.

[39] J. Böeseken and J. L. Leefers, Rec. trav. chim. 54, 861 (1935).

[40] A. Müntz, Z. Verein. Rübenzucker Ind. 26, 735 (1876).

[41] L. C. Jones, Am. J. Sci. [4] 7, 147 (1899).

[42] Merck Index, p. 338 (Merck \& Co., Inc., Rahway, N. J., 1940).

[43] E. Fischer and R. Stahel, Ber. deut. chem. Ges. 24, 2144 (1891).

444] Methods of Analysis, 6th ed., p. 805 (Assoc. Official Agr. Chem., Washington 4, D. C., 1945).

[45] A. Atterberg, Z. anorg. Chem. 48, 367 (1906); A. Laurent, Ann. chim. phys. [2] 67, 218 (1838); M. Dukelski, Z. anorg. Chem. 50, 38 (1906).

[46] F. P. Treadwell and W. T. Hall, Analytical chemistry v. II, p. 533 (John Wiley \& Sons, Inc., New York, N. Y., 1935).

Washington, October 7, 1947. 